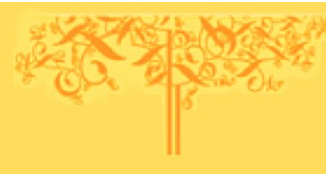

education review // reseñas educativas

a multi-lingual journal of book reviews

editors: gustavo e. fischman / melissa cast-brede / gene $v$ glass

Supported by the Mary Lou Fulton Teachers College, Arizona State University

\title{
Training Research and Development: Retrospective of a Career in the Defense Department Dee H. Andrews
}

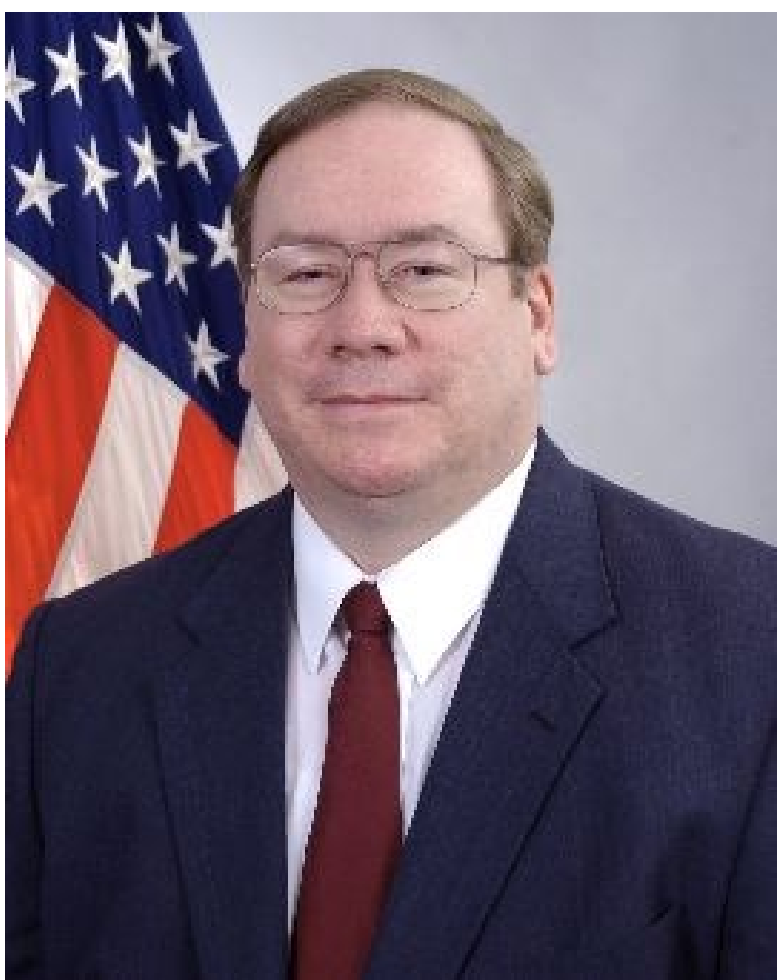

\section{Introduction}

I have had the privilege of spending a psychologist's career serving the men and women who give service to our nation. Starting as an instructional psychologist, I've also been called upon to learn skills in the human factors and industrial/organizational psychology domains. I've been placed in numerous situations as a team member and leader where I learned how to work with multi-disciplinary teams of engineers, physicists, computer scientists, logisticians, and contract specialists. During 34 years as a Department of Defense (DoD) researcher and manager performing training research and five years working as a contractor since my retirement from the DoD, I can truly say it was a rare day when I was not enthused to go to work. I hope in this paper to show young educational researchers and psychologists why I was excited about my own career path and suggest reasons why they might want to consider a similar path for themselves.

Our military forces must maintain a high level of knowledge and skill in performing increasingly complex tasks, with sophisticated tactics and equipment that require innovative approaches to mission solutions. Training and education are key contributors to mission accomplishment and success. New training methods and training equipment (e.g., simulators, training devices and computer-based instruction) must be continually designed, developed, assessed, and modified in order for personnel to learn and retain skills vital to this end.

The DoD employs a large cadre of scientists of various stripes to perform Research and Development (R\&D). Some scientists are in uniform, some are civil servants (my path), some are civilian contractors, and some are university professors and personnel. They cover many domains, including R\&D for space vehicles, air vehicles, propulsion, materials, sensors, directed energy, weapons, and cybersecurity.

The DoD has committed significant research funding to behavioral/human factors, which includes educational and training research. Some of the broad categories of psychological research are: 
A. Cognitive Readiness ("Cognitive readiness is the mental preparation (including skills, knowledge, abilities, motivations, and personal dispositions) an individual needs to establish and sustain competent performance in the complex and unpredictable environment of modern military operations," Morrison and Fletcher, 2002, p. 1)

B. Controls and Displays (how to establish the best human system interface)

C. Design: Tools and Techniques

D. Extreme Environments (operating in extremes of cold, heat, etc.)

E. Human Factors Psychology and Human Systems Integration

F. Human Modeling \& Simulation

G. Human Performance Measurement

H. Personnel Selection \& Classification

I. System Safety, Health Hazards, Survivability

Training may best fit into the cognitive readiness and human factors psychology categories; however, it has a place in all the behavioral categories above. I've always been fascinated by the way people get things done, especially those that require complex functions and tasks. Military personnel have many tasks to accomplish. Some are done on a regular basis such as maintenance of equipment (e.g., aircraft and avionics), and some are done only rarely (e.g., troubleshooting equipment failures and planning operations). However, all these functions and tasks require knowledge and skills, many of which can only come through formal and informal training, and this is why I was so attracted to a career of improving training in the military.

There is a section toward the end of this paper with 15 lessons learned from my career. The lessons learned are best understood by first reading the content preceding it, but I believe the lessons learned will be useful to a psychologist in the early stages of their career even if the preceding material is not read. Although the examples I provide in the article are from the military context, many of the principles and lessons learned that I included can be applied to the civilian world just as well.

\section{My Educational Psychology Training}

I became interested in the field of psychology in high school (I graduated in 1970) after I came across Sigmund Freud's (1899) Interpretation of Dreams in the library. I was fascinated that Freud had developed a method for interpreting dreams through his psychoanalytic experience. I still look with fondness upon the volume even though I long ago came to believe that the validity of Freud's methods and conclusions were suspect. Nonetheless, the book got me thinking about the awesome nature of that three pounds of wetware we call the brain.

I majored in psychology as an undergraduate at Brigham Young University (BYU), where I graduated in 1976. I took the requisite freshman courses, including psychology 101. I then decided to go on a two-year church mission to England where I learned a tremendous amount about teaching, learning, and serving God and my fellow humans. It was a significant event in my life, and I found myself applying what I learned to my career on many occasions. The mission experience convinced me that I wanted to study psychology. I then returned to finish my bachelor's degree at BYU in psychology where I had greatly enjoyed studying different aspects of the field. I was first drawn to experimental psychology and enjoyed helping professors develop, conduct experiments and analyze experimental data. I conducted operant conditioning experiments with rats and chicks, and became very familiar with the operant conditioning Skinner box (Skinner, 1959). I had a professor, Paul Robinson, who was writing one of the first experimental psychology textbooks targeted at undergraduates, and he allowed some of us to help him edit the text (Robinson, 1976). I loved the idea of studying learning in all its manifestations. After those experiences I was intent on pursuing a career in experimental psychology.

$$
\text { Later in my undergraduate career I }
$$
was exposed to a branch of psychology that 
was devoted to improving human learning by combining psychological learning principles with educational concepts focused on human instruction. The field goes by a variety of names: instructional design and development, instructional science, instructional technology, performance improvement, instructional systems, and others. The field is eclectic in many ways and uses a variety of learning and teaching methods paired with instructional technology to make human learning more scientific and systematic. The approach is now widespread in training programs of all types for schools, universities, corporations, government, and the military. Learning theory is a fundamental part of the field.

After working with a number of BYU professors, including Drs. David Merrill, Harvey Black, and Rex Wadham, I decided to pursue graduate training in the field. At the time, there were a number of good programs in that domain. I chose to apply to and attend what was then called the Instructional Design and Development (IDD) Master's program at Florida State University (FSU). It was highly recommended by the professors I knew in the program at BYU, and a former alum of the BYU graduate program in Instructional Science, Dr. Richard Boutwell, was a professor in the FSU program. The FSU IDD program had some of the best known experts in the field including: Drs. Robert Gagne, Leslie Briggs, Robert Branson, Roger Kaufman, and Ernest Burkman. All of the professors had backgrounds in education and psychology. As someone interested in training, I was especially drawn to the fact that of the 14 professors in the program, all but one had had experience outside of the halls of academia. They worked for the government, the military, corporations, and research institutions. I was impressed by their knowledge about designing and conducting effective training. In addition, most of the professors had degrees in experimental psychology, so we received a heavy dose of skills concerning research design and statistical analysis all aimed at allowing us to develop and use a research base to design better instructional techniques.

In the late 1960s and early 1970s the FSU IDD program was a leader in developing systems and models for constructing systematic instruction. The U.S. Army funded a significant effort at FSU which resulted in the Interservice Procedures for Instructional Systems Development (IPISD; Branson et al., 1975.) The IPISD model, still in use today, has five phases that lead to quality instructional design and development. The phases are:

$\begin{array}{ll}\circ & \text { Analysis } \\ \circ & \text { Design } \\ \circ & \text { Development } \\ \circ & \text { Implementation } \\ \circ & \text { Evaluation }\end{array}$

The IPISD model is often referred to as the ADDIE model taking the first letter of each of the five phases.

Analysis. In the analysis phase of the ADDIE model the instructional problem is identified. The instructional goals, success metrics, and overall objectives are established. Information regarding the learner, the "training audience," and the training environment is also identified during this phase. It includes learners' preferences, demographics, and existing knowledge and skills.

Design. The design phase of the ADDIE model nails down learning objectives, instructional methods and activities, storyboards, content, subject matter knowledge, lesson outlines, and media assets.

Development. The development phase of the ADDIE model is where instructional designers develop the content and learning interactions outlined in the design phase. During this phase, content is written and graphics, audio, and photography are also produced and assembled. 
Implementation.

During the implementation part of the ADDIE model, the instructional designer delivers the content and materials to Learning Management Systems (LMS) or directly to the trainer for live training events. The instructional designer also provides training needed by trainers, facilitators, subject matter experts or instructors.

Evaluation. During the evaluation phase of the ADDIE model, the instructional designer determines what success will look like and how it will be measured. Often times, the evaluation consists of two phases: formative and summative. Formative evaluation is iterative and is done throughout the design and development processes. This occurs throughout the ADDIE process. Summative evaluation consists of tests that are done after the training materials are delivered. The results from these tests help to inform the instructional designer and stake holders about whether or not the training accomplished the original goals outlined in the analysis phase (Instructional Design Central, 2016).

Each of the five phases has subphases which consist of steps that, if followed as closely as possible, hold promise of producing job incumbents who can do their jobs competently. I have used the ADDIE model throughout my career and found it extremely helpful in the design process. A powerful feature of the ADDIE model, and just about every other systems approach to training design, is that the phases and sub-phases are iterative. (Figure 1) That is, revisions to the instruction are made based on data collected during the design, development and evaluation process. The designer doesn't have to go in lockstep from the first phase to the last, but can move forwards and backwards as the process proceeds.
1

ANALYSIS
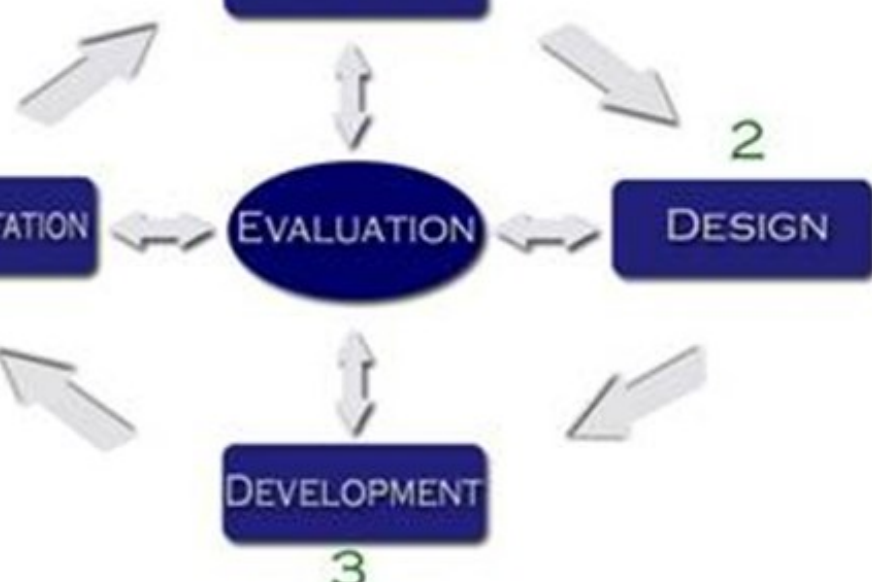

Figure 1. Iterative nature of the ADDIE model (Instructional technology services, Texas A\&M University. Retrieved from itsinfo.tamu.edu)

I was fascinated by the ADDIE model and other models that apply a systems approach to instructional development. Models for training and education have been developed and used by universities, companies, research centers, and many other organizations. As I researched those in existence in the 1970s, it seemed that more and more were being developed all the time. Some of the models were completely original while most them were modifications of models that already existed, such as the IPISD model developed at FSU. Modifications were often made for specific challenges or roadblocks that were encountered by different organizations when designing instruction.

I was curious as to why there were so many, so I started to make a collection of them. I soon found dozens of them. I thought it would be helpful to the instructional design and development community if I were to publish an article that related the many models, their origins, underpinnings, purposes and uses, and documentation. A fellow student, Ludy Goodson, and I set about finding and analyzing over 70 different models. We 
finally settled on 40 models that were categorized into four main and 11 subcategories. One of our major findings was that no model had information that allowed us to state whether the model satisfied all eleven sub-categories of our taxonomy. In many cases we believed the models might have addressed all 11 sub-categories, but the models' documentation was deficient. I suspected it at the time, and during my career I experienced a number of occasions when insufficient documentation made it difficult to use a particular model. We published an article on our analysis in 1980 (Andrews \& Goodson, 1980).

I had the great privilege of having

Dr. Robert M. Gagne serve as my major professor at FSU. Dr. Gagne passed away a number of years ago, but he is still recognized as a worldwide scholar on learning science, and his books are still widely read. It is from him that I gained a greater understanding of learning theory and how it could be applied to form the foundation of effective instruction. He introduced me to the concept of simulationbased training with a seminal article he published in the American Psychologist in 1954 titled, "Training devices and simulators: Some research questions". Despite over 60 years of research on simulation-based training since the article was published, a number of Gagne's fundamental questions have still not been completely answered.

Two of his main contributions were his five-domain learning taxonomy, and his theories about the conditions of learning (Gagne, 1985; Gagne, Briggs, \& Wager, 1992). Both drew heavily on learning theory and empirical data. The five domains of the taxonomy are:

- intellectual skills (discriminations, concrete concepts, abstract concepts, rule using, and problem solving),

- cognitive strategies (skills by means of which learners regulate their own learning processes)
0 verbal information (facts and knowledge)

- motor skills

- attitudes

Gagne and his colleagues set forth a variety of recommendations for building instructional systems that were based on the learning domains and the concept of learning conditions.

My time at FSU convinced me that I wanted to go into the training field. Almost every project I worked on after graduate school was heavily influenced by what I learned from the faculty at the FSU IDD department.

\section{Work as a Navy Training Developer and Training Researcher}

I was fortunate to have a number of job offers coming out of my Ph.D. program in 1979. I wasn't interested in going the professor route although I do enjoy teaching. (I've taught as an adjunct professor for 11 universities since I graduated.) Primarily, I wanted to get my hands into practical training development and training research as soon as I could. Some of the job offers were at university instructional development centers, others with industrial/corporate concerns, but due to my interest in all things military I decided to go to work for the Navy in a civil service job.

I went to work as a GS-11 for the Naval Training Systems Center (now called the Naval Air Warfare Center - Training Systems Division) in Orlando, Florida, in 1979. I started in the Training Analysis and Development Division. As the name implies, we were tasked with analyzing training requirements for new and existing training, and developing training system designs to meet the requirements. This is where I had my first interactions with large teams of designers, engineers, logisticians, computer programmers, subject matter experts, and others. It was a great experience learning to work with experts who came at the problem from different orientations. I learned that while the instructional systems 
business tries to be as data driven as possible in using front-end analysis data, other disciplines are not always inclined to trust front-end data, whether it be analytically or empirically derived, and least of all data provided by folks with educational or psychological backgrounds like mine. I was discouraged about this at first, after putting lots of time into what I believed to be quality data based front analysis, but I soon realized that I would have to adjust to other perspectives and expectations if I were to get my analyses used in training development for actual military jobs.

Developing training systems that will deliver the required training is a complex process. That is true in both technical development itself and management of development. In some cases, we used teams of designers from the Navy (civil servants and uniformed personnel), sometimes we let contracts and had contractor designers perform the work, and often it involved a combination of in-house and contractor personnel. It depended on the size of the project and whether the Navy had the money to hire contractors for a particular job. I discovered that a combination of inhouse and contractor personnel from various disciplines made for fascinating team dynamics, but we were all able to pull together for the basic objective - trained and effective personnel. Later in my career as I became the team manager for these large teams this early experience was vital. I spent three years in the Training Analysis and Development Division and worked on some fascinating projects. I was able to use all I learned in graduate school about analysis, design, and evaluation. I especially called upon what I knew in instructional media selection. The military is very equipment based. The reader is of course familiar with the tools of the trade, such as tanks, ships, airplanes, etc. Each of these has many primary systems, subsystems, and component parts. The military has to train personnel to both operate and maintain these many different systems. Hence, the military's need for simulators and training devices to aid in the training. My job was to help determine what training requirements had to be met, and, just as importantly, which requirements had to be trained in formal training settings (the military calls these formal settings, "school houses"), and which could be met informally through on-the-job training. A word about the difference between "training devices" and "simulators". Often these two terms are used interchangeably, but I always tried to help people understand that there is a significant difference (Andrews, 1988). A simulator replicates equipment and environments. So, we would build an exact replica of an aircraft cockpit, with the appropriate switches, buttons, knobs, dials, instruments, etc. In addition, we now can build out-the-window visual displays that have a high degree of fidelity with the real world outside the cockpit. We can also precisely simulate motion cues via large motion platforms, radio calls can be exactly replicated, and even odors can be produced in the simulated cockpit such as the smell of an electrical fire. All of this can be done at costs that have declined steadily over the years, but still constitute a significant amount of money. However, simulating all the equipment, environment, and cues exactly may not produce the skills and knowledge we desire trainees to acquire. On quite a few occasions I've come across simulators that were great at replicating cues but didn't lead to systematic learning. They lacked tools to help the trainee and the instructor measure training performance and advance learning. Use of the ADDIE model can lead to the development and implementation of these tools for simulators. It is when we can effectively combine good instructional design and training features with good simulation that we produce a training device.

Years ago Semple, Cotton, and Sullivan (1981) provided a representative list of necessary instructional features:

Instructional support features include ... hardware and software capabilities that permit instructors to manipulate, supplement or otherwise 
control student learning experiences. The instructional features ... are freeze; automated demonstrations; record and replay; automated cuing and coaching; manual and programmable sets of initializing conditions; manual and programmable malfunction control; aircrew training device mounted audio visual media; automated performance measurement; automated performance alerts; annunciator and repeater instruments; closed circuit television; automated adaptive training; programmed mission scenarios; automated controllers; graphic and text readouts of controller information; computer controlled threats; computer managed instruction; recorded briefings; debriefing aids; and hardcopy printouts. (page ii)

A good set of questions and answers about instructional features and simulation in general can be found in Best, Galanis, Kerry, \& Sottilare (2013). The features listed above can turn a simulator into a training device. Too often simulators lack the above capabilities. They represent cockpit and visual cues precisely, but lack features that enable learning. Oftentimes, the features are not included because a proper front end analysis, as defined in the ADDIE model, was not performed to identify the specific tasks to be trained. Consequently, the necessary instructional features were left out of the design. Sometimes not enough money is allocated to design and add the necessary instructional features. Too many simulators are delivered to training school houses that don't provide what instructors and trainees need, and the simulators end up being used as "room dividers" and "plant hangers". I exaggerate with those phrases, but poor or no front-end analyses and lack of instructional features and measures can sabotage a simulator that could be used for training. So, our job was to argue to the simulator design team, with front end analysis based facts, about how a training device should be designed that would truly deliver effective training with instructional features.

I only half-jokingly have said that we too often skip a proper front end analysis, build the simulator, then go perform a "rear end" analysis where we try to figure out what functions and tasks the simulator can actually be used for to train the trainees. I call this "rear end analysis" approach "training proctology". Convincing decision makers to allow enough time and resources to conduct a proper front end analysis is imperative if we want to avoid this regrettable approach.

Throughout this paper I have added pictures and graphics of training devices and simulators to help illustrate the types of systems I worked on while in the Training Analysis Division of the Naval Training Systems Center. Some of the pictures depict actual devices I helped develop, and others depict a general type of device that I worked on. In some cases, I couldn't find an actual picture of a device that I worked on because they are now out of the inventory.

\section{Maintenance Training}

This instance concerns a MK-92

Fire Control system on a Navy Frigate. A Fire Control system consists of a set of equipment, including radar and various computer systems that allow ships' weapons to be accurately aimed and fired.

The maintenance training device we developed for the fire control system allowed maintenance personnel to learn how to perform prescribed maintenance functions and troubleshooting. It allowed trainees to use both real and simulated test equipment such as voltmeters, oscilloscopes, ohmmeters, and multi-meters to test various parts and pieces of the simulated electronic equipment. After our analysis, we considered performing all of the training via Computer Assisted Instruction (CAI), but finally determined that the solution should be a combination of CAI with flat panels for indicating test points so that the trainees 
could connect the actual test equipment to the test points and take readings.

Figures 2 and 3 depict the types of electric test equipment used to test many types of electronic gear. Figure 4 (next page) depicts a training device that allows trainees to learn how to test various trouble spots while also learning to perform routine preventive maintenance functions. It measures trainee performance and keeps detailed training records for the maintenance instructors.

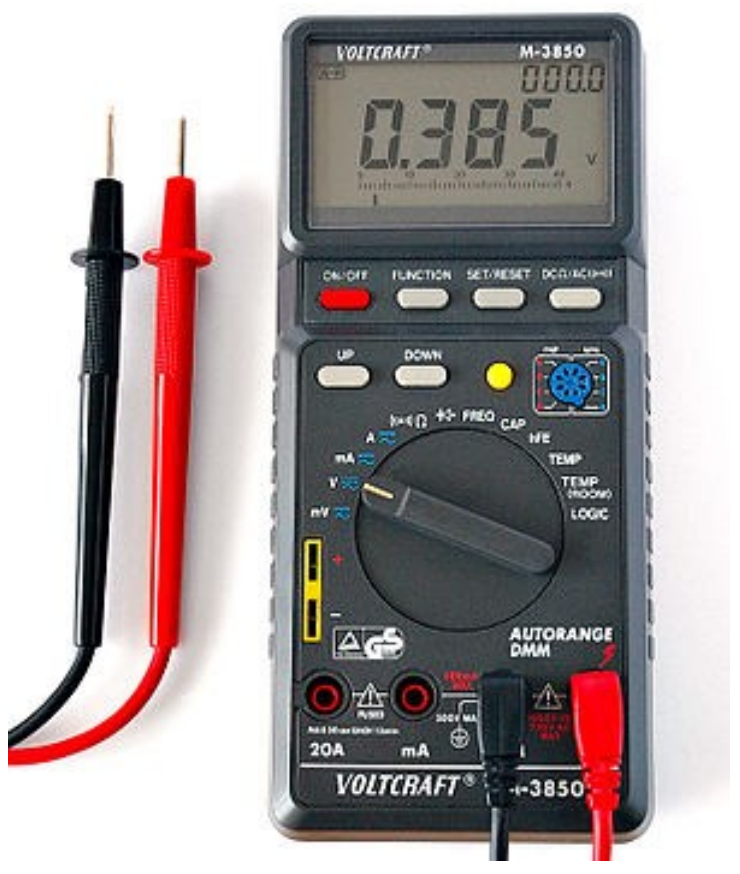

Figure 2: Actual Voltmeter

When I first went to work for the military there was a thriving line of research that sought to determine the effectiveness of maintenance training devices. For example, Orlansky and String (1981) published a report that summarized 12 such studies and found that maintenance training devices were just as effective for training maintenance tasks as using the actual equipment. In addition, these devices were less expensive to procure than using actual equipment for training. Through the years since the Orlansky and String report there have been a number reports with essentially the same finding.
Maintenance training research was a "hot" research topic from the 1980s to the early 1990s, and all of the services' (Army, Navy, Air Force) training research laboratories had large research programs. Alas, interest and work in this vital area has dropped off considerably since then, although there are some exceptions. That is unfortunate because maintenance is a critical component of mission success, and important research topics in maintenance remain to be addressed.

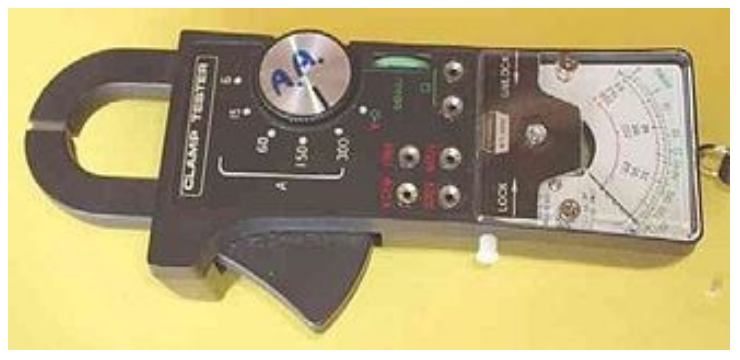

Figure 3: Simulated test equipment

\section{An instructional challenge with} maintenance training. Maintenance on complex systems like the Fire Control System discussed above can be divided into two types: field and depot. Field level maintenance is performed at the site where the equipment or system is used. Field maintenance can be either routine or it can consist of troubleshooting a faulty system. Field level is most often done by a uniformed military member of the training audience for whom the training was developed. Depot level maintenance is performed in a location removed from where the system is used for its mission. Depot level maintenance is performed either in a repair facility run by the military or in a factory. Depot level maintenance is performed by highly trained and experienced personnel, be they military or contractors.

The true challenge in training field level maintenance personnel is troubleshooting system faults and failures. Routine maintenance is highly proceduralized and documented in technical manuals, which maintainers will have in hand-typically in electronic form. 
Maintainers perform routine maintenance frequently enough to prevent a steep forgetting curve for what they have learned. However, fault troubleshooting is done only when the fault appears, which will be less frequent. Forgetting curves for fault troubleshooting skills may be steep because they are so rarely required. Steep or not, these curves are needed to properly schedule refresher, or sustainment, training. As I have worked on maintenance training programs, a key requirement has always been to teach basic principles about how complex systems operate. Troubleshooting these systems can follow different routes depending on the problem. It is usually not possible to teach all troubleshooting routes trainees may encounter in the field, so it is important that they have a fundamental understanding of basic electronic and mechanical skills.

Maintainers go to a basic school to learn such principles before they receive advanced training for a specific system at a specialized school. The basic school usually lasts about three to four months. The advanced school for a particular system can last for many months beyond the basic school.

Because the time spent in both schools is relatively short and considering the complexity of many systems, instructional designers who are designing training for the advanced school are well advised to determine just how many of the underlying principles trainees retain after they have finished the basic school. It may not be extensive since the basic school is relatively short. In that case, some of those underlying principles may not be re-taught in the advanced school so that the trainees learn strategies for troubleshooting problems they have never seen before when they get to the field. These strategies should be based on sound fundamentals as opposed to what is called "Easter egging" - a troubleshooting approach wherein the technician in the field isolates the problem down to a few possibly faulty components and replaces them one at a time to see if that fixes the problem. Such a strategy might work, but it is inefficient and may actually damage the system.

A key decision designers of training devices and other instructional techniques must make is how much "lock step" versus "free play" to build into the system (Andrews \& Windmueller, 1986). As the name implies, lock step instruction takes the student down a fixed path of lessons

Figure 4: Virtual Maintenance Trainer

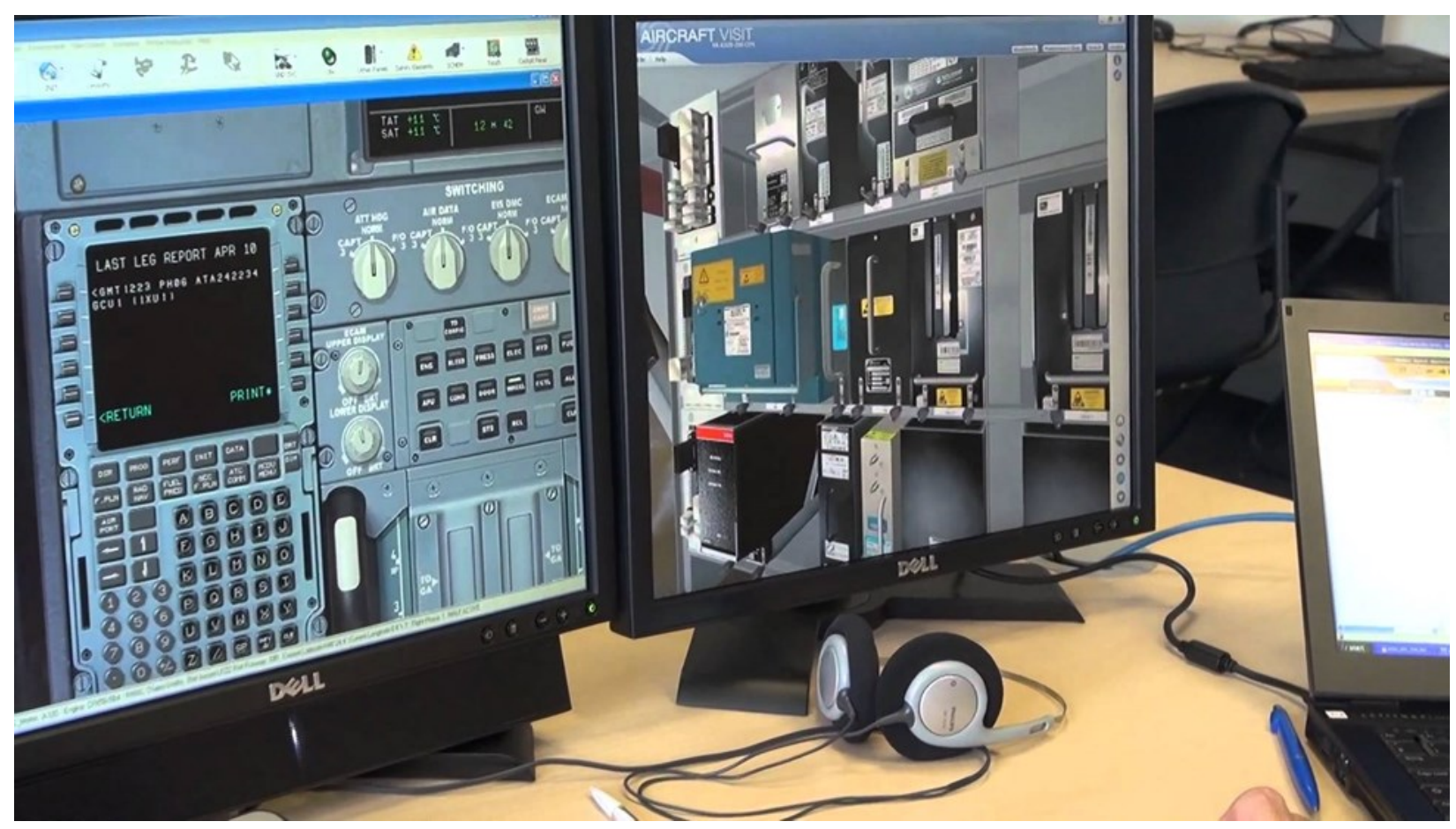


without opportunities to deviate. Such instruction is good for regularly scheduled routine maintenance task training. Free play allows the lesson structure to take the student where their good actions and errors would take them on the actual equipment. Such free play systems provide remedial aids to the trainee after errors, but the designer may structure the lessons so that it allows the trainee to go down a wrong path a way before correction is provided.

\section{Firefighting Training}

One of the most hazardous tasks Navy personnel have to perform is fighting fires that break out on ships, submarines, and airplanes. What makes the task especially dangerous is that these fires are often in very tight spaces below deck. The space to maneuver firefighting personnel and equipment is limited, and the lighting may not be operable in those spaces. In addition, due to personnel limitations on vessels, specialized firefighters are rarely on board. The fires are fought by personnel who normally have other duties as their prime responsibility so that they seldom get a chance to practice firefighting for different types of fires.

Traditionally firefighters were trained using fire pits filled with flammable substances that when lighted would allow trainees to get a sense of how fire retardant could be applied to put out a fire.

However, the traditional approach had three major disadvantages, the fire pits polluted the environment, the fires were not controllable once lit, and trainees were not given realistic firefighting venues that duplicated the cramped conditions they would find aboard ships. A solution was to build a re-usable structure in which non-polluting fires could be simulated using substances like propane. Figure 5 shows such a simulator on which I worked. The reader can tell from the many burned areas around the openings to the structure that some fierce fires have been ignited inside. Figure 6 shows trainees fighting such a controllable fire in a room similar to the interior of a vessel. Instructors typically would be in the space with the trainees instructing them (loudly and physically) by showing them how to man the hoses. In addition, instructors in a control room turn the flames on and off to control the intensity of the fire. They typically have cameras that not only allow them to see the progress of the fire fight, but also are used to record the action for later post training debriefs with the trainees.

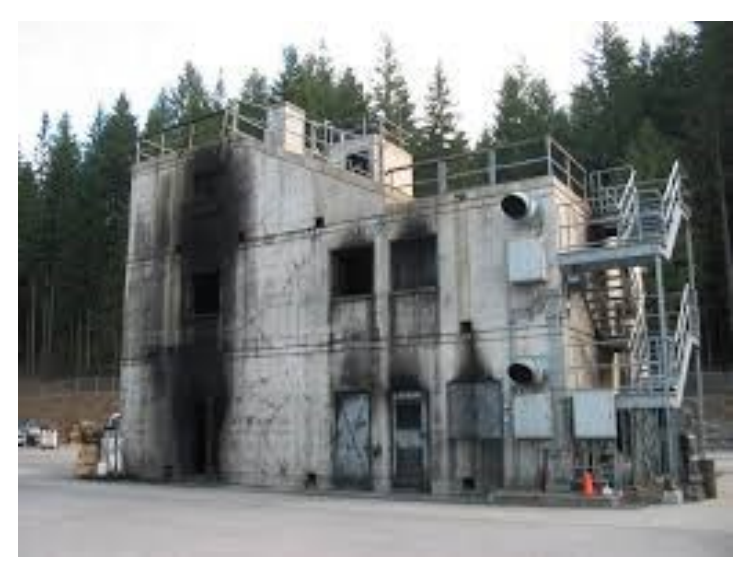

Figure 5. Firefighting training structure that uses clean propane gas

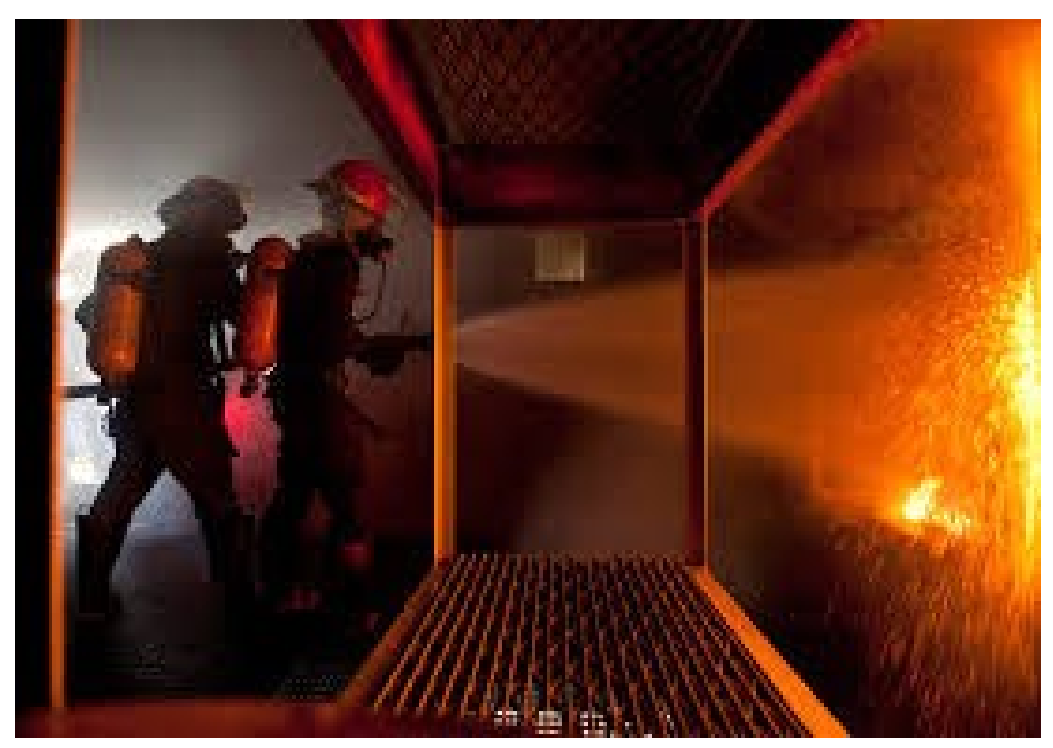

Figure 6. Inside a firefighting training structure 
Firefighter training now includes realistic virtual environments. Figure 7 shows an example. In this approach, actual fire retardant is not dispensed by the trainees, but is visually simulated. However, the effectiveness of different retardants can be simulated for different types of fires.

Fire fighter training devices can save lives, money, reduce pollution, and, with the addition of instructional features, they improve training effectiveness. to whether the simulator "feels" like the real piece of equipment when it's used. This last type of fidelity can be very difficult to get right because the expert may not be able to articulate what is wrong about the way simulator feels to them (Hays \& Singer, 1989).

As we worked on various training solutions for the fire fighter instructional system we had to think about the best medium for the different tasks to be trained.

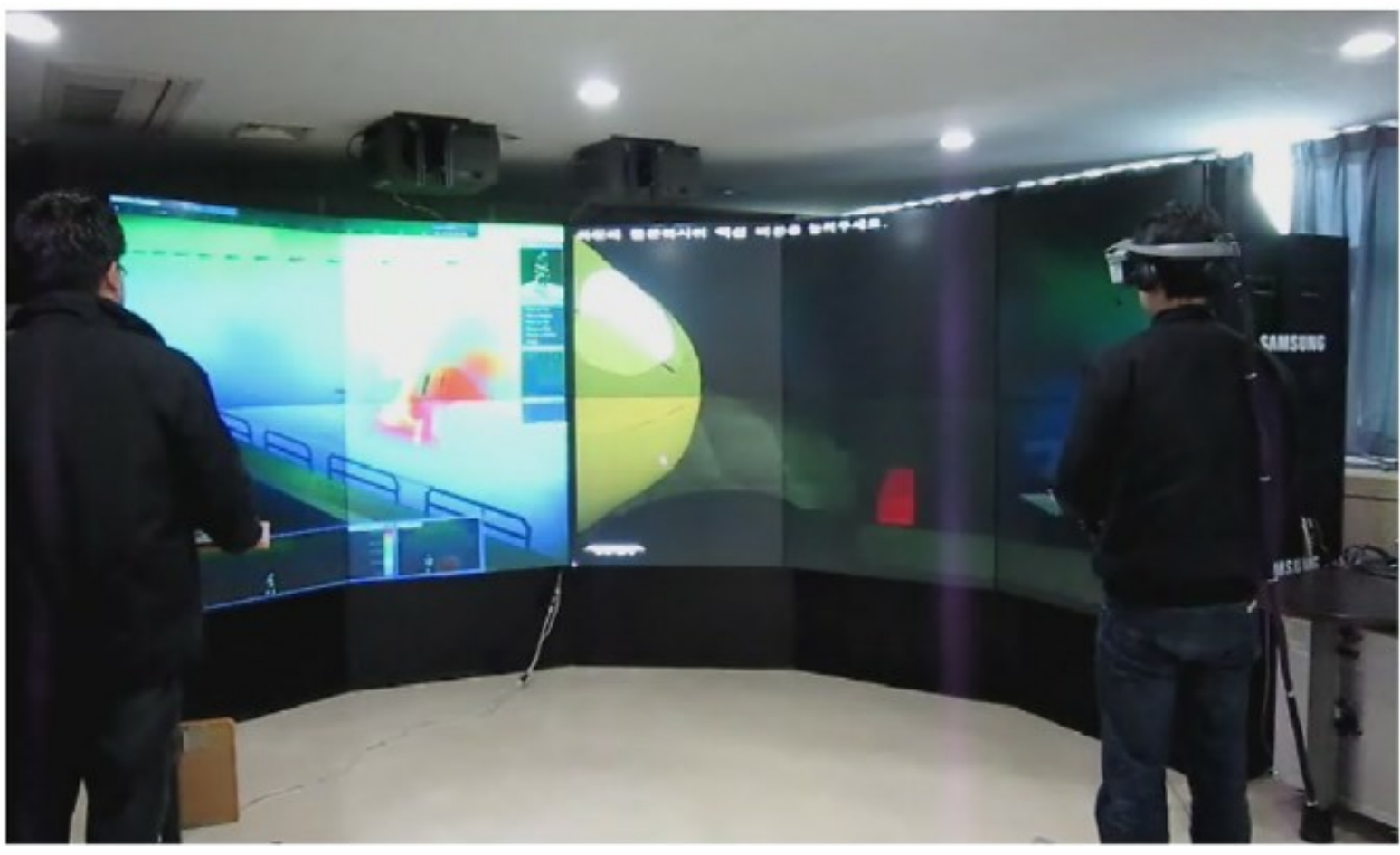

Figure 7. Virtual firefighting trainer

\section{Instructional challenges with}

firefighting training. Fidelity is a term heard often in the training device and simulator arena. Fidelity refers to several different issues. Physical fidelity typically means that the simulator "looks" like the real piece of equipment. For example, all the switches, knobs, and dials on a simulated fire hose control panel are in the same layout and locations as the real control panel. Functional fidelity typically means the simulator performs like the actual piece of equipment performs. So, when I trigger the simulated fire hose it sprays out a simulated stream or image of stream of fire retardant material. Finally, psychological fidelity refers
We developed a media selection tool that allowed us to consider the main characteristics of the task and determine where best they could be trained. Our media consisted of classroom instruction and demonstrations by an instructor, computer assisted training, a fire structure where different types of fires could be simulated and different types of fire retardant could be sprayed, and finally a pit fire (even when we did the analysis, government authorities were becoming increasingly concerned about the pollution caused by pit fires.) Today one would also have to consider the media of virtual reality, as shown in Figure 7 , and augmented reality.

Our media selection tool helped us to make reasonable decisions about which 
tasks were taught where. After trying the training in a formative evaluation setting, we then had the information to move some tasks to more effective training media within our suite of possibilities. These fidelity selection decisions attend all instruction, but they are especially important in the training device and simulator business. The fidelity definitions and discussion apply to all the training devices and simulators discussed in this paper.

\section{Team Training Devices - The 14A12 Anti- submarine team trainer}

Teamwork plays a major role in military operations as in most other activities. Whether it is a two-man machine gun crew all the way up to a major exercise involving thousands of participants, teamwork and its attendant team training is of major concern. Task work is what an individual does as part of the total team function. Training devices have been built for many task work training requirements, such as the maintenance training device described above. Paris, Salas, and Cannon-Bowers (2000) provide a good definition of teamwork:

Teams are more than collections of individuals and teamwork is more than the aggregate of their individual behaviors. Moreover, one cannot simply label a group of individuals a 'team' and expect that they will perform as a team. Specifically, one may conceive a team to be a distinguishable set of two or more people who interact dynamically, interdependently, and adaptively toward a common and valued goal/objective/mission, who have each been assigned specific roles or functions to perform, and who have a limited life-span membership (p. 1052).

For example, an individual fighting a fire must learn how to operate the nozzle of the hose dispensing the fire retarding agent. That is task training for an individual.
However, when that individual works in a team of firefighters, each individual not only has to perform individual tasks, but must also learn to perform interdependent, coordinated team tasks so that the team works as one.

I worked with a number of team training devices in the Navy. A good example was the 14A12 Anti-submarine warfare (ASW) team training device shown in Figure 8. 
Device 14A12 (Fig. 7) simulated the sonar stations for a number of different sonars, as well as other equipment used to analyze signals and launch weapons of different types when necessary. A typical sonar team for all the stations usually includes two to three dozen people. Training scenarios in a team trainer like the 14A12 can last for several minutes to two to three hours depending on the training objective.

\section{Instructional challenges with} team training. A major goal of team training is to help the team form a shared cognition (Cannon-Bowers \& Salas, 2001; Salas \& Fiore, 2004). Shared cognition is what allows a team to build a shared mental model (Cannon-Bowers, Salas, \& Converse, 1990). Each member of the team should have an understanding at some level of the tasks that other team members must perform if the team is to successfully accomplish its mission. Each team member should know what pieces of information the other team members need from that team member, and when they need it. This included the teamwork required for communication. Team training device simulators can be very helpful in allowing the team build shared cognition and situational awareness. Endsley (1995) defines situation awareness as, "knowing what's going on ... the perception of the elements in the environment within a volume of time and space, the comprehension of their meaning and the projection of their status in the near future" (p. 36).

The individual members of the team must be competent in their own task work, and also in the teamwork capabilities that require an understanding of what the other team members require and are doing (Salas, Cooke, \& Rosen, 2008). The training challenges for teams in the military are especially acute because military teams seldom stay together very long. For example, in the anti-submarine warfare case, a team of a dozen or more sonar operators and team chiefs may only be together as an intact team for a short time. Members may only be together for a few weeks or months before one or more team members departs due to new assignments, retirements or separations from the service, combat casualties, or one of many other possibilities.

Team training devices, like the 14A12 are located at training sites in the US, but many months may pass between a team's visits to the training site, either because the ship is deployed or the team members are tending to needed equipment upgrades and other duties when the ship is in port. Even then, there is no guarantee that all team members will attend the training session together because some members may be absent for various reasons. Building solid team cognition in the team via training is essential and difficult.

One potential solution to the problem is to embed training capability into the actual equipment the team uses on board ship (or, aircraft or tank, etc.) so teams can conduct operations training so they can have the advantage of instructional features and performance measurement whether in port, at sea, or while preparing for a mission. The military services have installed embedded training capabilities in some cases, especially the Navy, but overall the use of embedded training has been far lower than originally desired (Alexander et al., 2014).

Much team training happens in the field, not in the school house. Therefore, the instructional tasks normally assigned to a full-time instructor fall to leaders within the unit. These leaders often lack formal instructor training. They can, nevertheless, be effective instructors, but receiving instructor training improves the chances of effectiveness. In some units such training for instructors may be given, but often it is informal and less effective. Use of computer-based training could be helpful to these senior personnel in learning instructional tasks, but I have rarely seen it used.

\section{Ship Handling Training}

After three years in the Training Analysis and Development office, I moved to the Human Factors Research and 
Development Laboratory within the Naval Training Systems Center in 1983, and received a promotion to the Civil Service Grade of GS-13, equivalent to a Major in the Air Force or Army, and Lieutenant Commander in the Navy. I was excited to move to an $\mathrm{R} \& \mathrm{D}$ position because it allowed me to devote full time to exploring new theories, concepts, and technologies. One of the great advantages as a scientist in the Department of Defense is the ability to modify budgets for laboratory equipment, including computer capabilities that a scientist can access. Although the scientist has to compete within the DoD for funds, I've always perceived that task to be easier than it is for university professors because the government scientist is closer to decision makers and the source of funding. In my career as a government scientist, I seldom lacked resources after I made a cogent case for how the funding would enhance mission effectiveness and success.

Another interesting piece of research I pursued was developing a training system for Navy personnel who were responsible for guiding huge vessels safely both into and out of harbors and while they are on the open water. Improved training was needed because high profile accidents had increased. These accidents caused significant damage to ships (both own ship and other vessels), and to piers and other objects in the water. There were also some ship groundings. Accident investigations revealed that a number of the accidents involved a shortfall in ship handling knowledge and skills on the part of the officers who were "conning" the ship from its bridge. These officers are responsible for determining the proper course for the ship and giving the crew orders for speed and direction. These are not easy skills to learn because the huge size of many Navy vessels makes their responses to commands sluggish, ocean conditions are always changing, sand bars shift, the behavior of other vessels may be erratic, etc. I was tasked with analyzing the available training, and conducting an $\mathrm{R} \& \mathrm{D}$ program to develop alternative training solutions.

At the time of the R\&D program there were several large "full bridge" simulators that were being used in the US to train mariners in ship handling skills. The surface Navy (ships traveling on rather than under water) was not making regular use of these training devices (Figures 9 and 10).

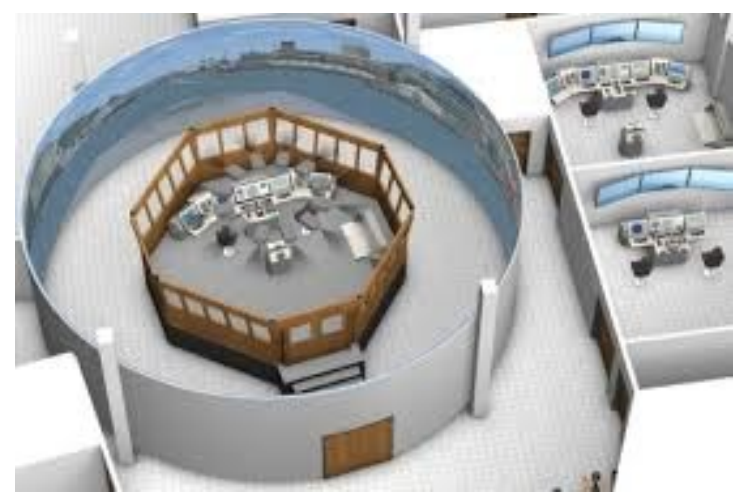

Figure 9 (top). Bird's Eye View of a Ship Handling Training Device

Figure 10. (bottom) Ship Handling Training Device - scene looking out window shown in Figure 9.

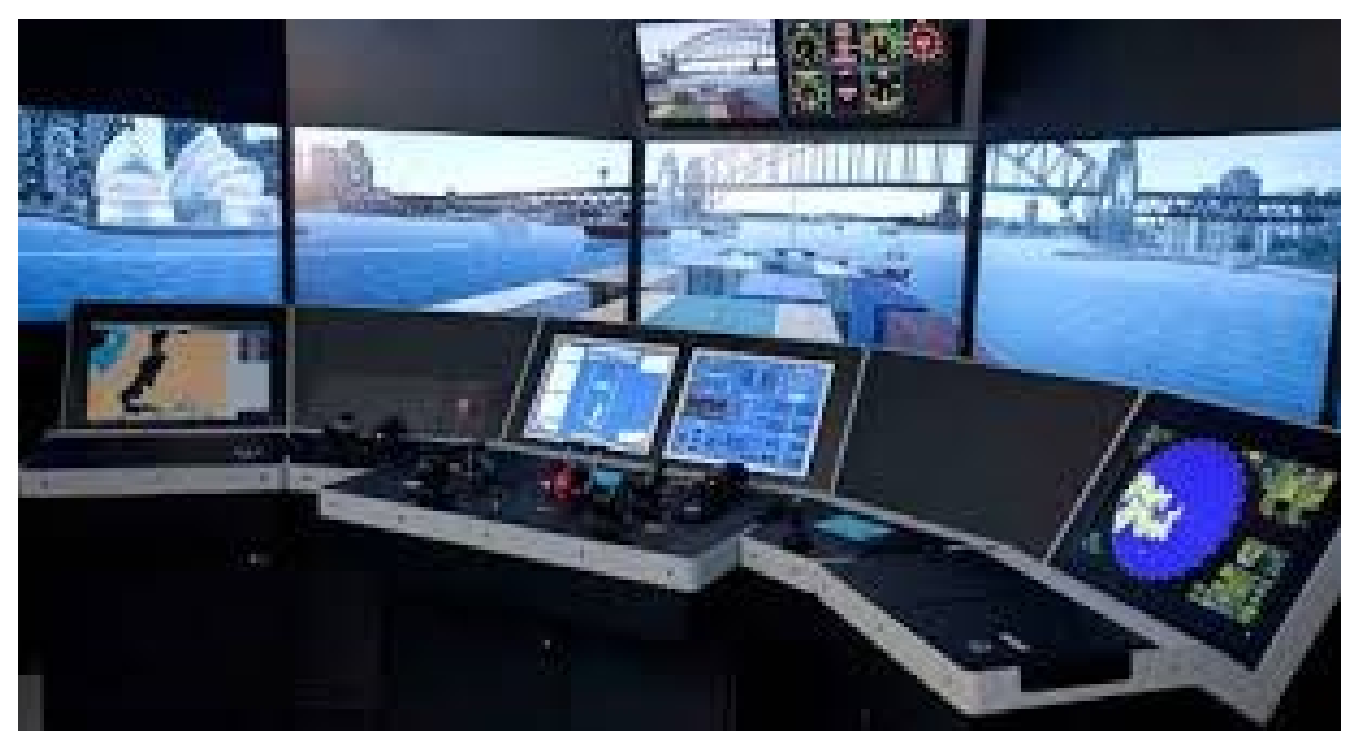


Junior submarine officers were using a device at the Maritime Academy on a regular basis. The surface officers received ship handling training in relatively small boats during their initial training, but they did not have access to the modern ship handling training devices of the time.

With the aid of contractor personnel who had ship handling expertise, I performed a task analysis using the ADDIE method to identify necessary ship handling skills and the knowledge required to perform them. This task analysis was validated by Navy ship handling experts. We then set about developing a training device that was considerably smaller than the large ship handling simulators then available. Not only was the goal of the R\&D to provide effective training, but the Navy was also interested in developing a more affordable solution than the available multi-million-dollar training device. We

developed a training device that had a footprint small enough to fit on a table top. Its scenes were driven by a computer generator representing the various ship controls and displays one would find on any ship bridge. We called it a part-task trainer because it did not simulate all of the controls and displays represented on the full task training devices as shown in Figures 7 and 8 above, but it did simulate tasks that the task analysis showed to be those most crucial for successful ship handling. We conducted a trial to determine if trainees learned the necessary skills while using the part task training device, and to see if ship handling instructors gained enough information on the learning state of the trainees to make the device worthwhile. The answer to both goals was affirmative (Hanley \& Andrews, 1987).

The analysis and R\&D led the Navy to work with a ship handling simulator company to build a simulator where Navy officers received their initial surface training.
The Navy then leased simulator time for the trainees to train as needed. The lease approach allowed the Navy to avoid a multimillion-dollar buy in any particular year.

Today, the Navy makes use of different simulation approaches for ship handling training, including virtual reality technology so that the Officer of the Deck can train while looking through a virtual reality visor (Figure 11) to see the visual cues necessary to make ship handling decisions. It makes use of the part-task training concepts we developed many years earlier with $\mathrm{R} \& \mathrm{D}$ on part-task training.

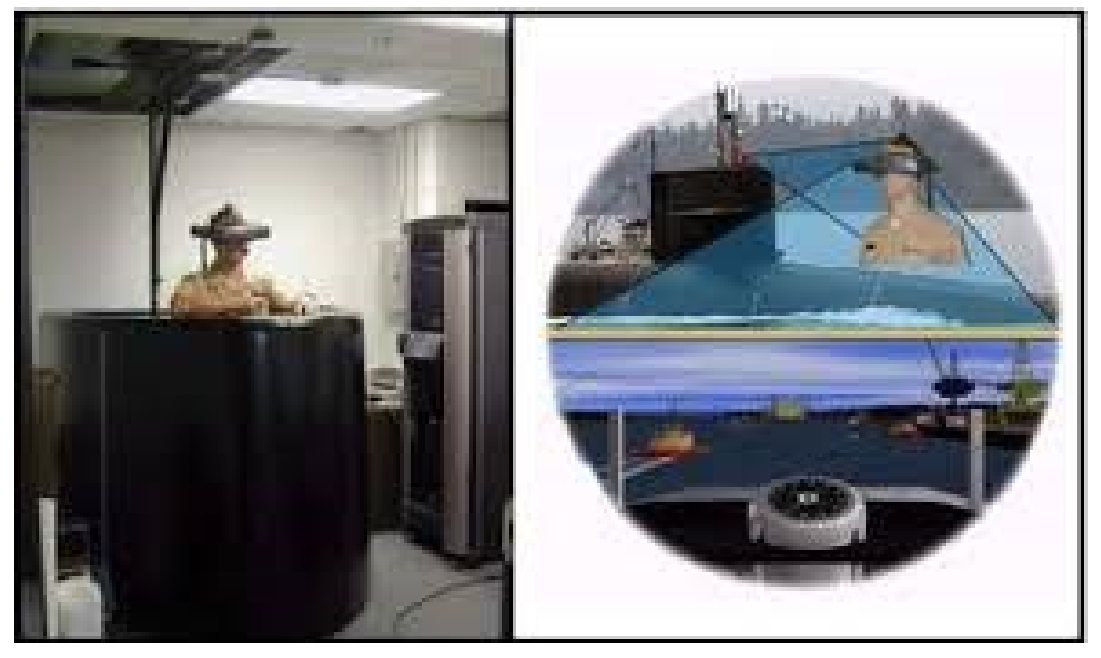

Figure 11. Virtual reality ship handling trainer using head mounted visor

Instructional challenges with ship handling training. Ships are relatively slow moving. Teaching relative motion is a challenge for trainees who lack an innate understanding of the concept.

Relative motion is the calculation of the motion of an object with regard to some other moving object. Thus, the motion is not calculated with reference to the earth, but is the velocity of the object in reference to the other moving object as if it were in a static state. For example, a person sitting in an airplane is at zero velocity relative to the airplane, but is moving at the same velocity as the airplane with respect to the ground. Relative motion is a concept, and its calculation occurs with relative velocity, 
relative speed, or relative acceleration (which is the change in velocity divided by the change in time. (Chegg, n.d.)

Many ship

collisions occur because those who were navigating the vessels lacked situational awareness due to a lack of relative motion understanding. Ship handling simulation training devices are ideal for teaching the concept because the scenarios can be run over and over until the concept is understood by the trainee. Once understood, the concept of relative motion is fairly robust and not particularly prone to decay. Our main challenge was to determine how often personnel should receive training on relative motion to refresh their understanding of the concept. Our research showed that training should occur at least once a year with challenging conditions (e.g., fog, heavy winds, shifting currents) in the simulator.

Another training challenge is to ensure that trainees understand the physical effects of underway replenishment (UNREP). UNREP involves transferring cargo and people between two ships that are underway in the open sea. The Navy has to do UNREPs because their ships are often at sea without a friendly port where they can take on supplies. Supply ships must pull alongside the receiving ship and cargo is passed via cables and hoses strung between the ships. Ships cannot stand still for these transfers because the ships might be crashed together by the waves. They keep underway at speed so that those driving the ships can control the vessels. As shown in Figure 12, Figure 12. Underway replenishment

the ships are only a few yards apart during UNREP, and there can be a tremendous suction action between the hulls of the ships if they get too close. Training personnel to understand the various physical effects of operating large ships close together is a challenge. The hydrodynamic modeling of the software that runs the simulator must undergo considerable verification and validation testing to make sure the simulated effects are accurate.

\section{Tank Team Trainer Effectiveness Evaluation}

I was asked to assist the Army with a training effectiveness evaluation of a new training device that was being designed and fielded. The M-1 Abrams Tank Conduct of Fire Trainer (Figure 123) was a team trainer in that it had training stations for both the Tank Commander and the Gunner who fired the Abram's main gun. Both trainees 
had the visual displays, such as periscopes and windows that presented simulated terrain views. These scenes presented imagery of enemy targets, along with friendly and neutral vehicles. The Army provides gunnery training that builds from a simple set of tank tasks to very complex tasks. The Conduct of Fire Trainer allowed the Commander and Gunner to communicate as they would in a combat situation while they looked at the simulated scenery cues. The instructors had their own Instructor/Operator station from which they could call up different scenarios, monitor team performance with built in performance measurement tool, conduct replays of the training, freeze the scenarios, and make use of other instructional features.

We conducted a series of 30 interviews with sample trainees and instructors to get a sense for how well they thought learning was occurring from the use of the device. Careful notes were kept using an interview protocol. In addition, we examined pre-training and post-training gunnery scores in the simulator. Based on our analysis we made a number of recommendations about the design of the simulator, the performance assessment system, and the instructional features. The Army incorporated our suggestions into the design and use of the training device. The COFT is still in use today by the Army. The COFT allows the Army to train day and night in any weather because any operating conditions can be simulated. In addition, large amounts of money are saved by not using live ammunition and many miles and gallons of fuel are saved because a tank does not have to be driven anywhere or the gun used to fire actual rounds.

Figure 13. M-1 Tank Conduct of Fire Training Device

\section{Instructional challenges in tank} gunnery and command training. Modern weapon systems have become both more accurate and more lethal through drastic upgrades in technology. If a gunner shoots, chances are good that they will hit their target. Training individual task skills are important for gunners and tank gunnery simulation can be very helpful. The gunners can shoot many more practice rounds, and they can shoot them in all kinds of weather and terrain conditions. The real training challenge comes in deciding how often they need to practice in order to maintain their proficiency. The Army has "gunnery tables" that require gunners to qualify for increasingly difficult tasks. Starting with hitting one nonmoving target at a close range, the trainees must go through a series of progressions that end with some very difficult tasks like hitting multiple, moving targets at considerable range in increasingly difficult terrain and visibility conditions. How often do trainees and operational gunners need to practice these skills once they have been achieved? How should practice in a simulator and on a live gunnery range best be combined to achieve the optimal result? We can measure 
performance in a tank simulator very accurately, but how can we best measure team communication and command and control decisions by the crew?

\section{Instructor/Operator Station Design Guidelines}

Many training devices include an instructor-controller station for designing training scenarios tailored to each trainee, operating the training device, and instructing the trainee before, during and after training sessions. Often the training device will provide instructional support features.

For example, I found that training was not optimal because the Instructor/Operator Station (IOS) did not allow instructors to teach in the way they thought best. I began a program of research to develop IOS guidelines that could be used in training device design. To do so, I worked with a retired Navy Officer, Captain John Charles (Charles, 1984) who had extensive experience in designing IOSs both while in the Navy and later as a contractor. We reviewed previous literature on IOS design, visited many Navy training device locations to watch the IOSs being used, and interviewed a great number of instructors and operators who used the devices. Taken from the technical report that we produced, figure 14 shows an IOS for the COFT trainer described above and typical of IOSs found on many training devices.

Figure 14 Instructor Operator Station
A simulation trainer instructor/operator station incorporates features designed to facilitate and optimize the instructor/operator interface. Many types of instructional and operating features can be and have been implemented.

Although the majority of these features are intended for training elements used by the instructor, some of the features are primarily used by the IOS operator to support the training evolution. Thus the features incorporate both instruction and operation functions. We identified over forty features at the time.

\section{Work for the Army}

I enjoyed my time working for the Navy, and in 1985, after six and one-half years with the Navy, I was promoted to the Civil Service grade of GS-14 (equivalent to military grade of Lt. Colonel) and went to work for another R\&D organization, the U.S. Army Research Institute (ARI) for the Behavioral and Social Sciences. I worked for the ARI Field Unit in Orlando, Florida. ARI is the Army's premier lab for research and development in manpower, personnel, and training. It had a number of Field Units (now called Research Units) co-located with training posts throughout the US.

In my two and one-half years at the Field Unit, we were mainly focused on developing models that would help designers optimize the training effectiveness of training devices of all types,(Andrews, Singer, Ozkaptan, \& Hofer (1987; Sticha, Blacksten, Buede,

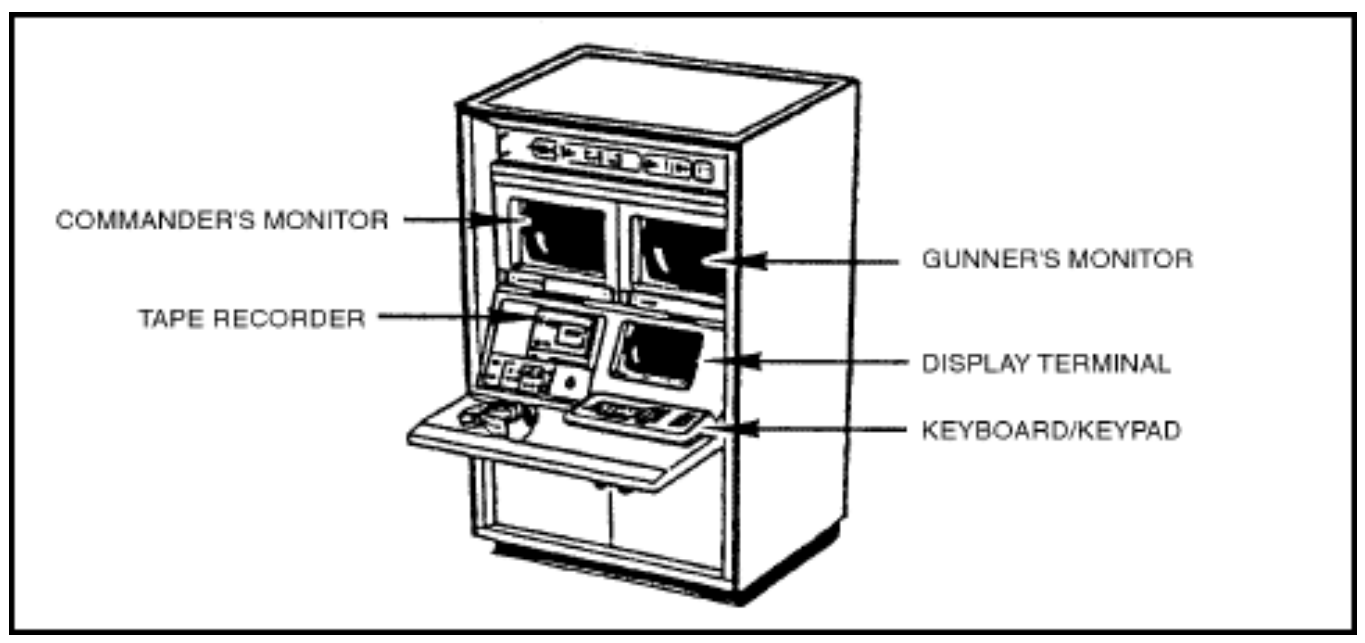


Singer, \& Gilligan, 1990). I was the team leader for the effort. Here is brief synopsis of this large research effort:

The Optimization of SimulationBased Training Systems (OSBATS) was designed to provide engineers involved in the concept formulation process for simulators and training devices, a tool with which to consider and tradeoff alternative features. OSBATS would enable engineers to trade-off fidelity and instructional features in the context of a training strategy to obtain designs that minimize cost for desired performance levels. OSBATS consists of five modules: a simulator decision module, a training device media selection module, an instructional features module, a fidelity optimization module, and a resource allocation module. The heart of the OSBATS model resides in the expert system rule bases used in the instructional features and fidelity optimization modules to make decisions about instructional and fidelity features to be incorporated in the simulator designs. (Singer, 1993, p.1)

The engineers and other professionals at PEO-STRI used the OSBATS models to improve training effectiveness. Working in the field of operations research and optimization for the first time was an enlightening experience for me (Radon, n.d.) It taught me much about building complex models and providing the models with data (both qualitative and quantitative) on which the models operated. That experience would be helpful to me throughout my career.

\section{Work for the Air Force}

In 1987 I came across a job announcement for the position of Technical Director at the Operations Research Division of the Air Force Human Resources Laboratory in Mesa, Arizona. I knew of the good reputation of the $\mathrm{R} \& \mathrm{D}$ produced by the Laboratory and applied for the job. I was excited when offered the job at the GS15 level (equivalent to Colonel). The Lab has gone through many name changes through the years. It is now the Warfighter Readiness Research Division of the Air Force Research
Laboratory (AFRL) at Wright Patterson Air Force Base. When I worked for the AFRL, our Division had about 100 military and civil servants, about 220 on-site contractors, and many more contractors around the country. The challenge of being the Technical Director was particularly interesting because of its multi-disciplinary mix of training specialists, military subject matter experts, engineers, physicists, computer scientists, and support staff. Hopefully, the need for all these specialties will be apparent as I describe the high technology work that the Division performed and is still performing.

We had good mix of different types of psychologists at the lab. They included, experimental psychologists, psychoperceptual psychologists, industrialorganizational psychologists, and instructional psychologist like me. As Technical Director, part of my responsibility was to do personnel planning for the Lab, deciding what types of positions we needed to fill in order to meet our R\&D goals. We first had to determine what the goals were, what types of disciplines we needed (e.g., behavioral scientists, engineers, computer programmers, etc.), then defend those positions to our management chain, and then find the right people for those positions. I really enjoyed that part of my job because we were not only meeting immediate needs, but laying the groundwork for long range $\mathrm{R} \& \mathrm{D}$ plans.

I felt that our job as behavioral scientists in the lab was to ask and answer the "so what?" questions about our R\&D efforts. In other words, so what if we could invent new simulation and instructional technologies, did those innovations make any difference in the training effectiveness of what we developed? So, I encouraged all our scientists and engineers, but especially our psychologists, to have that basic question in mind as we planned and did our research. That was always one of the first questions I would ask when I conducted program reviews with the scientists.

As the Technical Director my main lab goals were to: 1 . Produce effective training techniques and technologies, 2 . 
Perform basic research that would lay the foundation for applied research under goal number one, and 3. Develop new technologies that would reduce the cost of training for the Air Force. Our funding came from basic and applied R\&D funds that the lab received from Congress via the DoD and Air Force channels, and from funding we would get from the specific Air Force Commands who were our partners in developing better and more affordable training techniques and technologies.

Our funding allocations were usually in the 20-30 million dollar range each year. A major responsibility I had was leading the planning of the R\&D program and then justifying and defending that budget through our Chain of Command. I enjoyed the planning, usually five years or more, and then justifying and defending it. It gave me an opportunity to work closely with our scientists, engineers, and customers so that I could explain the program to our superiors who often did not have a background in our disciplines.

The main focus of the Lab when I arrived was on pilot and aircrew training research. The Air Force, of course, has a huge need for quality training for all of its pilots, of which there are several thousand if we count the pilots of Unmanned Aerial Systems (UAS), often referred to as drones. The training is quite expensive when done in an actual aircraft. For example, the cost to fly an F-16 fighter aircraft exceeds $\$ 6,000$ per hour, and the cost to train in a large multi-aircraft engine aircraft like a bomber or transport plane exceeds $\$ 15,000$ per hour. In addition, flying obviously has an element of danger, especially for those learning to fly. Also, flying pollutes the environment. And finally, pilots who are flying training missions cannot use all of their systems or tactics because of requirements for security. For these, and other reasons, pilot training turned to simulation early in its history. During World War II more than one-half million pilots were trained in the Link "Blue Box" trainers. (Figure 14).

The Blue Box did not have a realistic visual display because the technology was not available to provide an out the window scene. However, it did allow instrument and emergency procedure training. There were

Figure 14. Link "Blue Box" Trainer

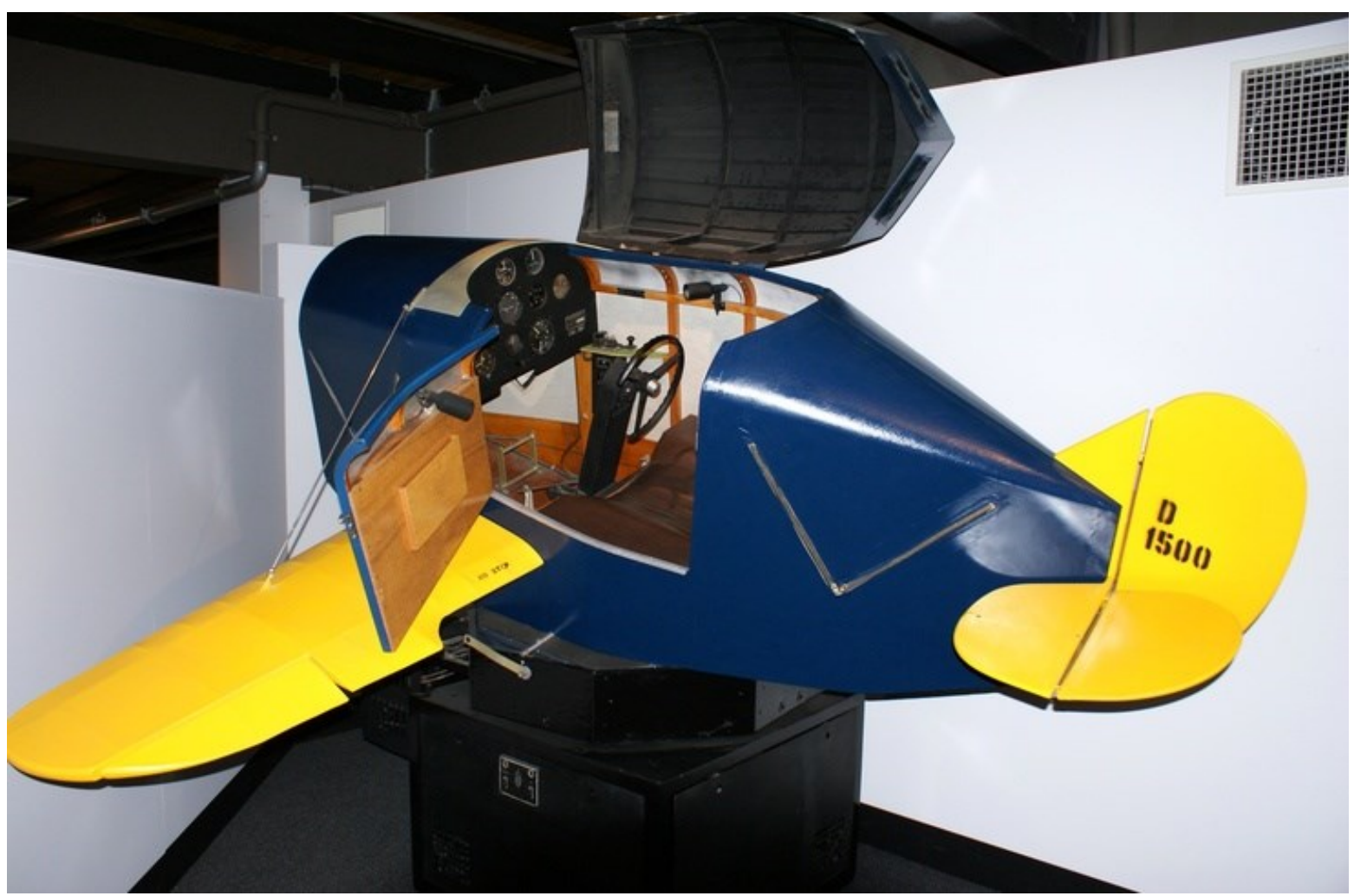


none of what today we would consider to be instructional features, and the instructor pilot was about the only source of instruction before, during, and after the training flight. The Blue Box did provide motion cues through three axes (yaw, pitch, roll), which was important for trainees

because understanding control inputs affect the aircraft's

orientation in the air is vital in learning to fly. Earlier I

mentioned that psychologists working with simulation technology must always ask and answer the "so what?" question about the training effectiveness of new technology. The "Blue Box" is a good example of why that question was so important. It is true that while the "Blue Box" was quite sophisticated for its day, it was relatively primitive compared to today's technology. However, for the tasks it was designed to train (emergency procedures, instrument flying) it was quite effective.

The Blue Box could best be described as a part-task trainer. The instructors of the day did not pretend that it could train all required pilot tasks, but it was effective at what it was designed for. At our lab we invested a good sum in understanding the part-task training concept better from a psychological point of view. To conduct the research, we built a variety of part task testbeds. Figure 15 shows an example of a part-task training testbed with a fighter simulator cockpit and a medium level of resolution out the window scene.

Note the myriad of button, switches, panels, control stick, and throttles the pilot must master. It is expensive to functionally simulate all of those features in a simulator cockpit. That level of fidelity may well be justified if the simulator is to be used for advanced training including combat skills. In the case of the fighter depicted, the Figure designers have chosen to provide a high level of cockpit physical and functional fidelity and a medium level of visual fidelity, largely to make the simulator more affordable. 


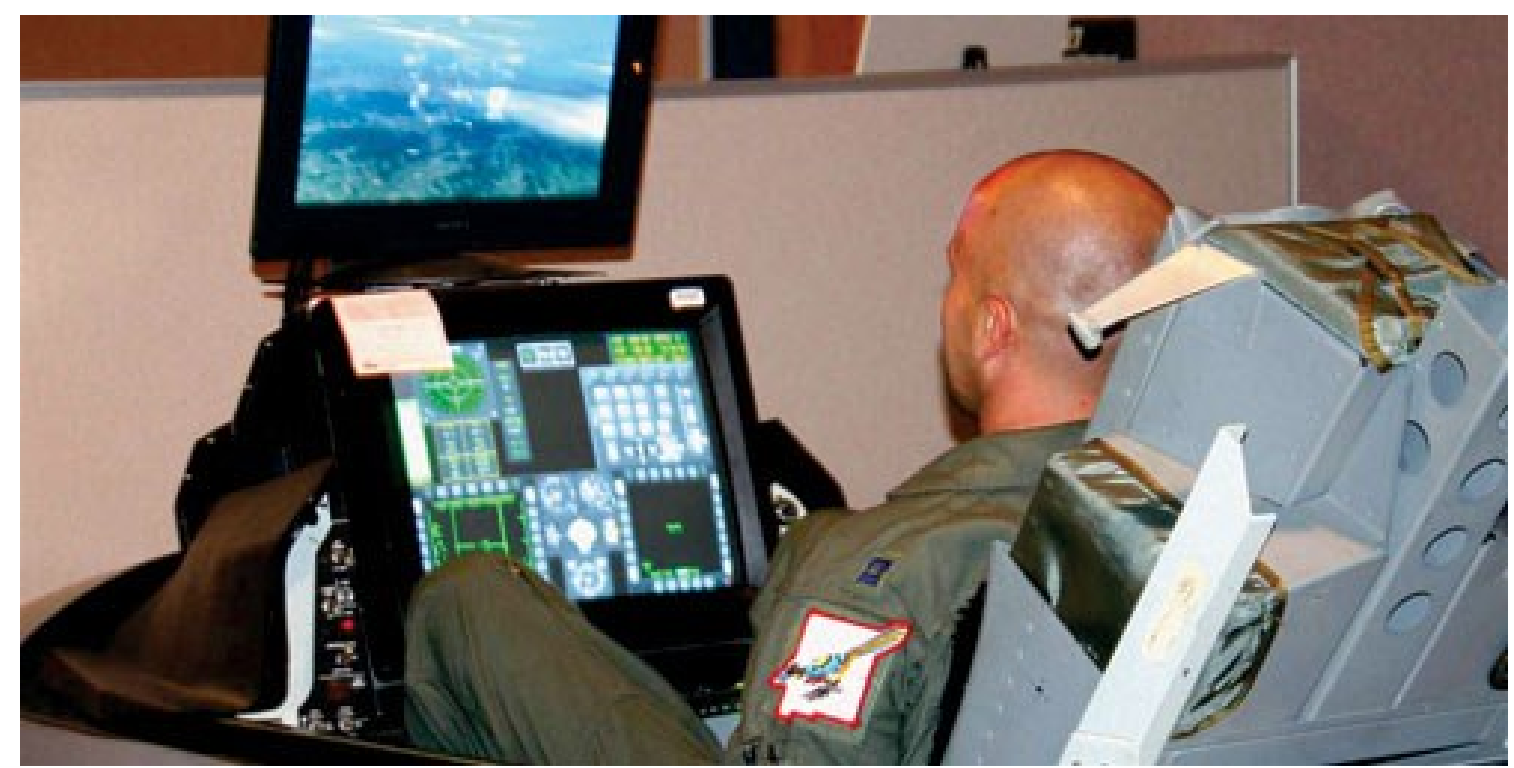

Figure 16. F-16-part task trainer

Figure 16 shows another approach to a part-task trainer test bed. Note the trainer has a small out the window visual, and its instrument display is a Cathode Ray Tube instead of true instrument displays with individual controls like functioning buttons. The display does have a simulation of Heads Up Display which provides the pilot with information like: flight path information, navigation information, targeting data, and angle of attack information showing the aircraft's relative angle to wind flow. We built the part-task training testbed to see if emergency procedures and other tasks could be taught effectively using the technology. For example, modern fighters have control sticks that have a variety of buttons much like a gaming joystick except they are much more complicated. The pilots have one hand on the control stick and the aircraft throttle, which also has various buttons. To operate the aircraft, the pilots must develop the skill to use the buttons in various combinations depending on which aircraft systems, radar, weapons systems, and anything else they need to operate. There are dozens of different control stick and throttle button combinations. Pilots learn to use the various combinations quickly and automatically almost without thinking. It is called "playing the piccolo", because just as effortlessly as a concert piccolo player must learn to play without really thinking about the notes, so must a fighter pilot learn to operate the various button functions while in flight, especially in combat.

Our work with part-task trainers had at least two R\&D objectives. We wanted to both see how effective they were for training and we wanted to lower the price as much as possible. Large, full mission simulators at the time were in the 10 s of millions of dollars range.

Dexter Fletcher, an editor of this series, makes an excellent point about judging the cost of simulation-based training. Cost is only half the issue - return from cost is the other. Return can be measured in monetary terms, which is not easy, but do-able. Return in operational effectiveness is harder, but the main issue. Consider how expensive our training ranges are. Operational costs are astronomical, but their operational value is obvious to every warfighter, so we pay them. Other forms of training are turned down because they "cost too much" (although not as much as our ranges). Where's our research to determine what they return? Where's our research on determining ways to assess operational return with respect to the cost of training? We should be answering the same question with respect to personnel selection, personnel classification, ergonomic design, 
job and performance aids, and other human centered investments we should be making. Who's assessing the trade-offs among these investments? (Fletcher, personal communication, 2016).

After World War II, and with the advent of computer technology, engineers and psychologists started to develop visual systems that could present out the window scenes to pilot trainees. By the time, I got involved with flight simulation, the field could present visual out the window scenes to pilots, but they were in black and white, and had a variety of resolutions and other challenges. In some cases, three dimensional large terrain maps were used to present a visual image to the trainees. These terrain maps resembled the type of simulated terrain, with towns, roads, rivers, and other features used today by model rail road

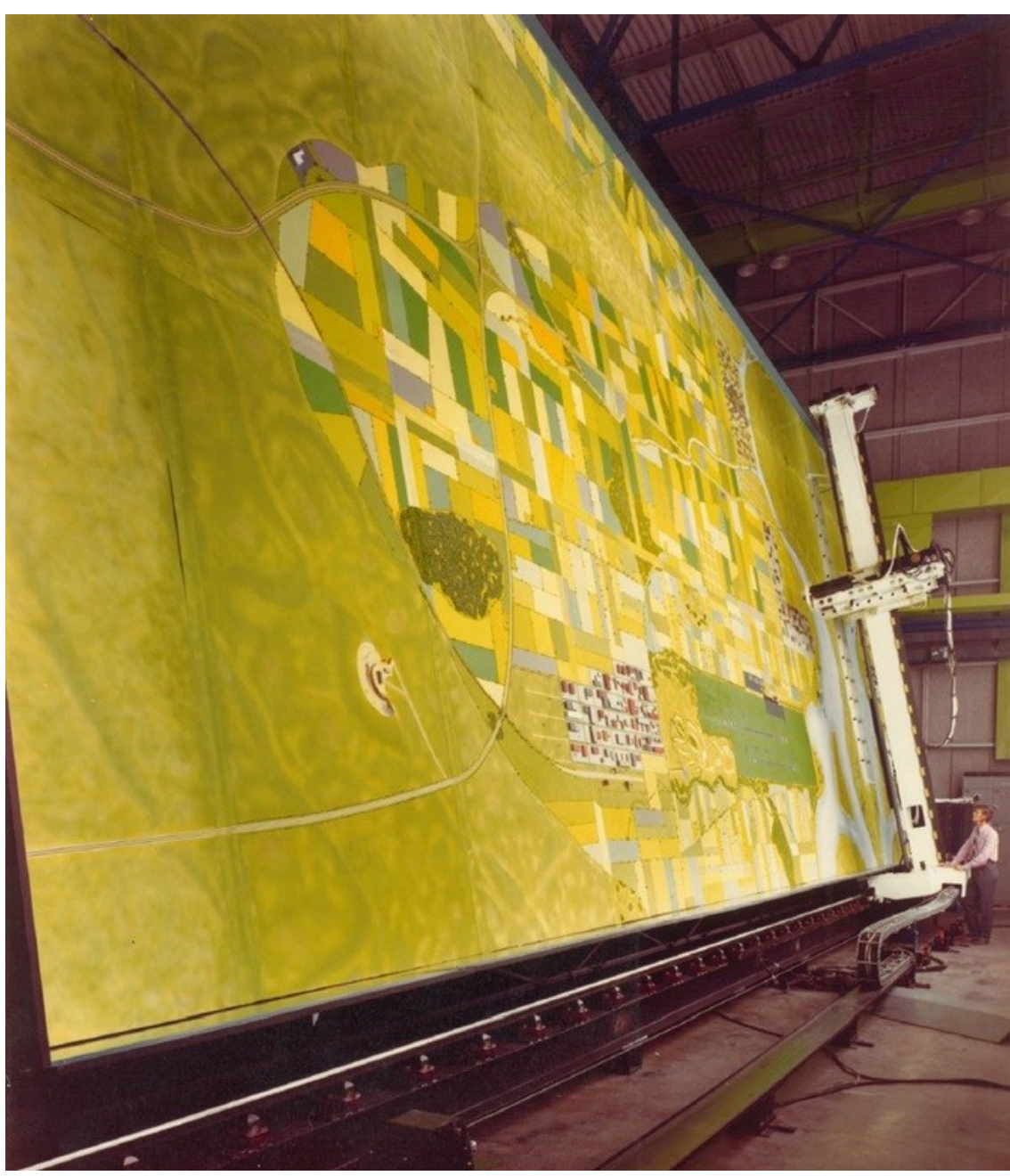

enthusiasts. A closed-circuit television camera would be maneuvered over the simulated terrain in coordination with the pilot's movements of the simulated aircraft's control stick, and the resulting picture would be displayed to the pilots in their out the window display. The resulting visual display had reasonably good resolution, but the terrain the pilot could cover was limited to the size of the terrain board which was usually about 12 meters long by about 4.5 meters tall, so the terrain board required a large building. Changing the model boards was required if the instructors desired the trainee pilots to fly over different types of terrain. I had familiarity with the terrain board from some work I had done with Army aviation. A three dimensional terrain board is depicted in Figure 17. Note the relative size of the man in the bottom right corner of the photo.

When I arrived, the Air Force Research Laboratory had an impressive history of investing in visual research and technology development intended to improve the quality and training effectiveness of visual displays for simulators. For example, the lab had developed the first color computer generated imagery (CGI) system. Much of the CGI technology so prevalent today for entertainment has been a spin-off from DoD investment. Years ago the DoD was spinning off results from $R \& D$ in simulation technology to the commercial world, and now, among other things, we are seeing our investments in new virtual reality technology

Figure 17. 3-D Terrain board for flight simulation visual scenes returning to military use. It shows that DoD research investment in technology can have 
a huge multiplier effect when it reaches civilian industry and application.

In my time as Technical Director the capability of visual simulation for flying training made huge advances. Simulator visual systems have three interrelated components: a visual display system, which can range anywhere from a head mounted display as is seen today in virtual and augmented reality; computer generated imagery, which calculates the scene and sends it to the projectors that drive the visual display; and the data base, which may represent a real world piece of terrain or a scene from the data base developer's imagination. I was involved in making resource decisions concerning where the lab would invest its visual R\&D funds. Which innovative technologies were promising? What visual research would help us to answer questions about the efficacy of new technologies? While our lab was certainly not alone in this $R \& D$, it is safe to say we developed a worldwide reputation for quality breakthroughs in a variety of areas. Figure 18 shows a scene from a modern flight simulator visual system with a level of fidelity that was not available when I arrived at the lab in 1988. Our lab had much to do with helping the field reach this level of simulation fidelity.

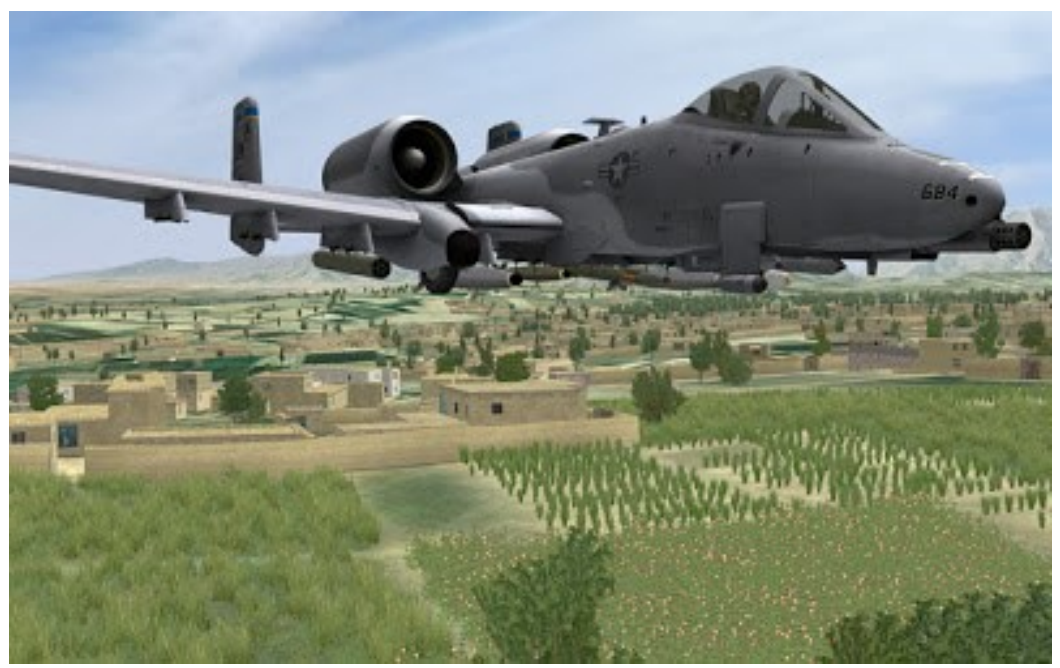

Figure 18. Current degree of visual fidelity in flight simulation
Our lab was heavily involved in networking technology improvements. When fighters go on missions they typically fly in four-ship formations. This allows for mutual support. A major challenge for those advocating simulation-based approaches to mission training was producing a four-ship simulation complex that was networked together. The network had to be incredibly fast because the mission demands that the data and visual scenes be updated 60 times per second (60 Herz). Any time lag in the network updates would cause jitter in the simulation, which would destroy the realism we sought for four-ship mission training. Based upon considerable investment by our lab and other organizations, we achieved the holy grail of a 60 Herz update rate for simulation networks. With that technology we were able to build an affordable fourship simulator testbed for F-16 simulators. That proof of concept testbed convinced senior leaders that at last full mission training could be performed in training settings other than just in the air.

This capability was important for a variety of reasons. Four F-16s flying on a training range cost at least $\$ 20$ - $25 \mathrm{~K}$ per hour. In addition, every hour the aircraft flies means that its total useful life is reduced by that hour. Also, flying over a training range has training limitations. There are classified tactics and aircraft sub-systems that can't be flown in open ranges because we don't know who might be watching and listening. Finally, safety limitations with live aircraft such as altitude restrictions mean that pilots can't really train as they will fight.

We conducted studies that showed that the simulators could be networked over very large distances and that they could be linked between continents and still maintain a secure network that updated the data between simulators at $60 \mathrm{~Hz}$. We called this type of training Distributed Mission Training and 
started to include other types of simulators in the network such as ground control and air control stations to direct the fighters as in the real world.

All the time our lab was making technological breakthroughs, our behavioral scientists were conducting research to ask and answer the "so what?" questions concerning training effectiveness. We brought many pilots into our lab and had them fly increasingly complex missions to measure their progress. We developed new instructional features to aid the instructor pilots as they conducted pre- and postmission briefs and debriefs.

Having laid out the case for simulation, I hasten to add that we never believed that simulation-based training could completely replace live training. There are important objectives that can only be trained in the air effectively. Physiological factors such as handling high $G$ loads are an example. Our goal, as was the case with the OSBATS simulation optimization research, was to arrive at an optimal blend of simulation and live training depending on the training objectives. We always kept that goal as a paramount principle in our research.
Our lab was heavily involved in the expansion of the Distributed Mission Training concept. Militaries around the world now use the expanded version and it is called Live, Virtual, Constructive (LVC) training. Live refers to training in actual equipment out on a training range. Virtual refers to training in a virtual world such as in the F-16 four-ship simulator. Constructive refers to computer generated forces that act in the training scenario as friendly or enemy or neutral air, land or sea entities such as aircraft, ships or ground vehicles. When all three LVC domains are combined, a powerful training environment is created.

The LVC concept is now used on regular basis for training in many militaries. It allows coalition forces in many countries to train together for missions without ever having to be in the same training range. Huge sums of money are saved, but, more importantly, research showed that the training effectiveness of LVC training was as high as it was when large forces were brought together.

Figure 19. This graphic depicts the LVC domains being combined to make a synthetic battlefield for training.

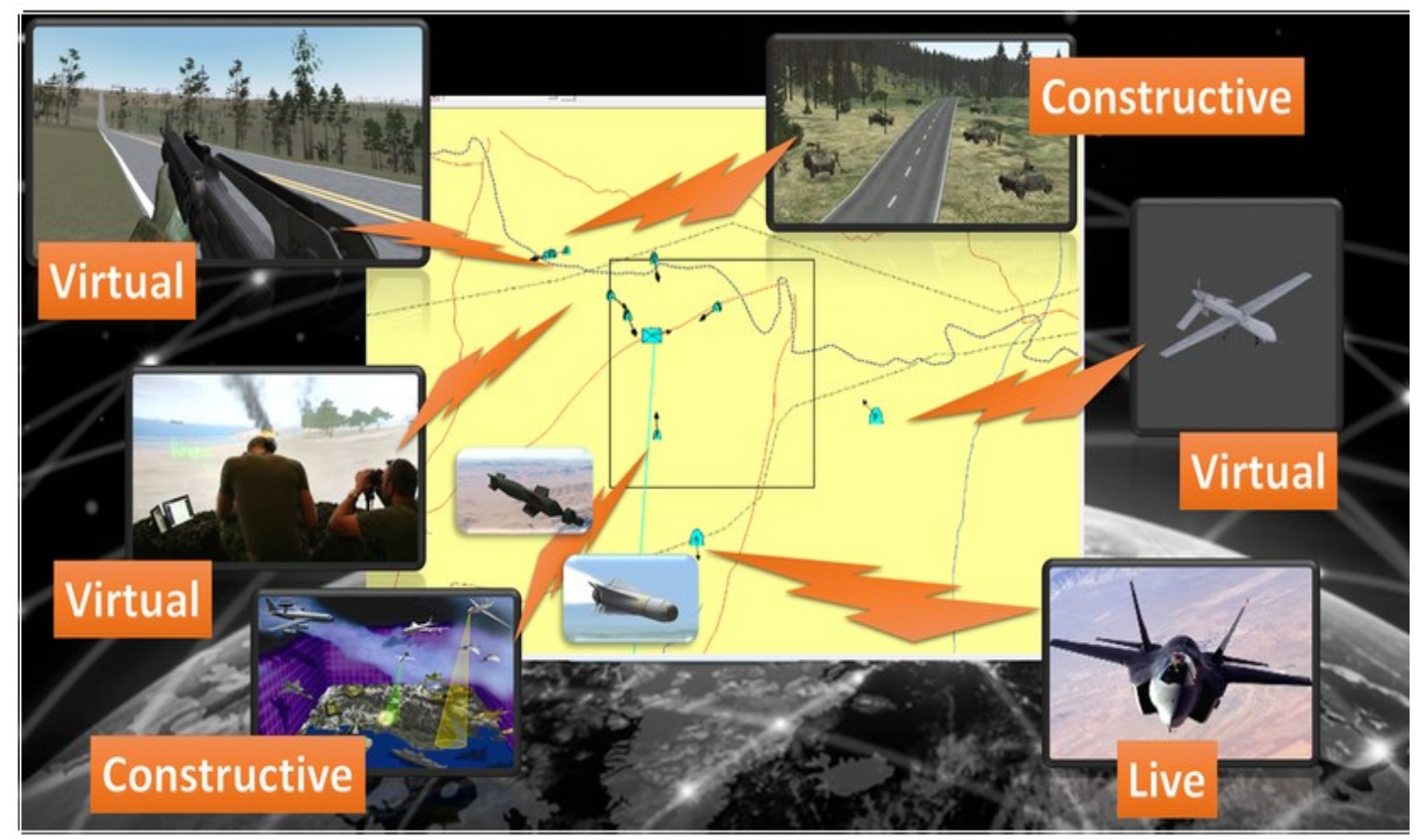


Figure 20 depicts a Combined Air

Operations Center where the Commander and the entire planning, command, and control staff are brought together to conduct a theater wide mission operation. The staff can consist of hundreds of different specialists. Militaries have conducted large scale command and control training exercises since the beginning of such operations. Now these large command and control centers can be linked to entities in ranges, both real and virtual, so that the entire command and control chain, down to individual operators in aircraft and on the ground, can train in a manner very similar to real missions.

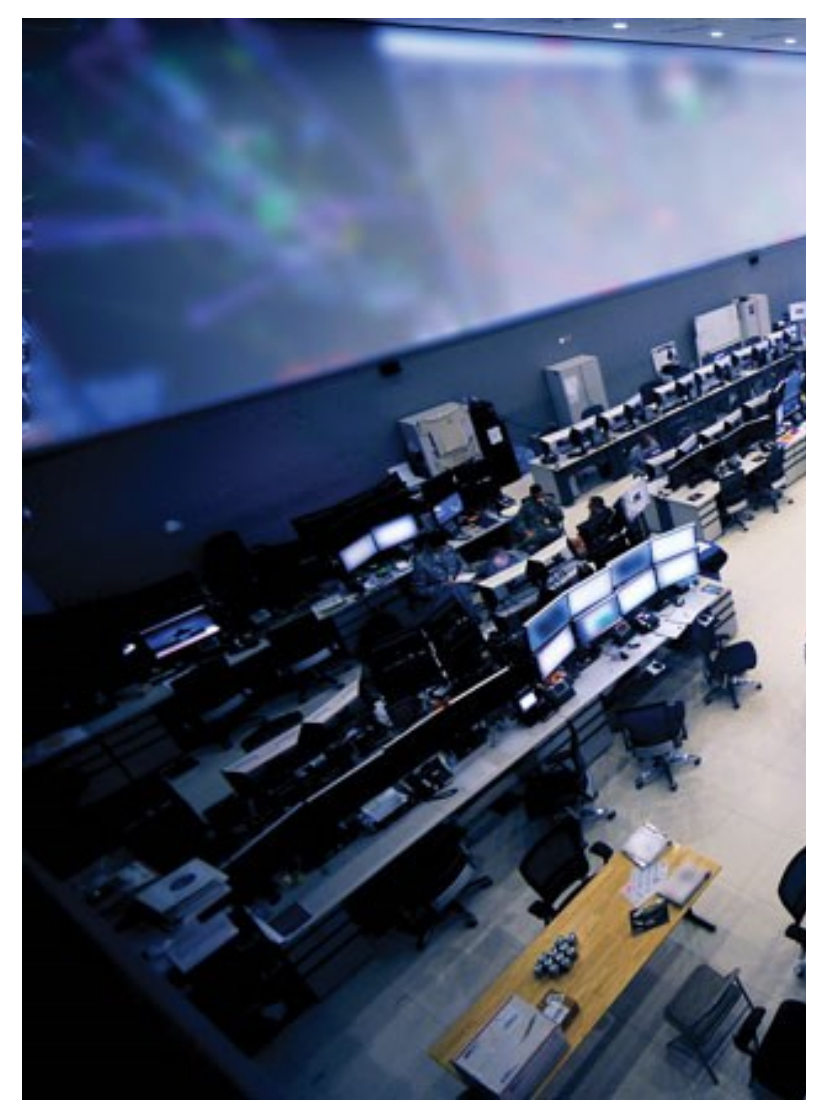

Figure 20. Combined Air Operations Center

I was the Technical Director of our Division of the Air Force Research Laboratory for 15 years and greatly enjoyed leading such a talented team. My last nine years were spent as a Senior Scientist (I was promoted to be a member of the Senior Executive Service Science and Technical Cadre with a grade equivalent to a Brigadier
General). I loved the job because I was released from management responsibilities and was given the task of performing research in any area I chose. I was given a small team of support scientists and a budget every year. During those years I did research in a variety of areas such as:

Training model development for a human factors tool called Manpower and Personnel Integration (MANPRINT) (Conant, 2014; Fitzgerald et al., 2008). MANPRINT is aimed at integrating into the system acquisition process considerations of human factors. All equipment developed for the military is made better when human factors such as; fatigue, skill requirements, communication requirements, human-system integration, reach and strength requirements, and hearing and considered in the design phase.

\section{Accelerating expertise} development (Hoffman et al. 2014; Hoffman, Andrews, \& Feltovich, 2012). Like all organizations, the military has great need to train service members more quickly. This project examined the learning literature, and provided prescriptions for accelerating the attainment of expertise.

\section{Training for supervisors to} mitigate cyber insider threat (Andrews et al. 2013; Greitzer et al., 2008). Insider cyber theft and sabotage account for about $40 \%$ of the cyber incidents that occur each year. Yet, supervisors are ill-trained to even detect, let alone mitigate, the threat. This work produced virtual reality training modules used to provide training to supervisors in this key area.

\section{Training to mitigate friendly fire} by improving combat identification (Andrews, Herz, \& Wolf, 2010; Wilson, Salas, \& Andrews, 2010). When a friendly soldier or force tragically brings harm to another friendly soldier or force, great regret follows. This work explored the role that better human factors analysis and training can and should play in reducing the possibility of friendly fire. 
Cyber-friendly fire (Andrews \& Jabbour, 2011). As I worked in the cyber warfare domain area it became clear that many of the same principles that applied to avoiding friendly fire in the traditional sense (e.g., an aircraft accidently shooting a friendly tank) could be applied to personnel conducting cyber operations.

\section{Embedded Training Guidelines.} (Andrews \& Roessingh, 2011). I worked on a NATO science panel tasked with developing more effective guidelines for designing training solutions into an actual piece of military weapons system. The goal is to allow personnel to conduct training in their weapon system. However, to do that, certain instructional features and performance measurement capabilities must be either designed into the system from the start or attached (strapped on) to the system if it already exists. Our guidelines examined the role of embedded systems and gave guidelines for their use.

Team training (Cooke, Gorman, Myers, Duran, \& Andrews, 2013; Cooke, Pedersen, Connor, Gorman, \& Andrews, 2006). As has been described throughout this paper, team training in the military is of great importance. Empirical research on the topic is developing, but more needs to be done. I sponsored a series of studies with Nancy Cooke and her lab at Arizona State University, examining the role learning retention plays in team training and how it can be strengthened.

\section{Storytelling as a method of} instruction (Andrews, Hull, \& Demeester, (Eds.), 2010; Andrews, Hull, \& Donahue, 2010). Through the years I have been struck by how much teaching and learning happens in the military via stories. Military personnel are constantly telling stories about their experiences in combat and at other times. It is a primary way that knowledge and wisdom is passed on. It happens both in formal classroom settings and in off-duty hours' venues. This research and resulting publications examined what literature there was on the topic and proposed a taxonomy of storytelling for instruction. The taxonomy consists of four distinct, but related, categories of storytelling for instruction; scenario based, problem-based, narrative based training and case based training.

\section{Fundamental (ab initio) pilot} training guides (Fitzgerald et al., 2007). Training novice pilots is a complex process. The instructor pilots are given a fair amount of leeway in judging the performance of novices, and therefore there is often an inconsistent approach to judging performance. This study produced a more objective approach based on trainees' behaviors during the training session.

\section{Lessons Learned}

After 40 years on working in the instructional psychology field it is interesting to look back at major lessons I have learned. These lessons are not just about developing effective instruction, doing training research, and applying training methods and techniques, which I to relate below. I've also listed some lessons on ways to be more effective as a developer, researcher, and manager.

Envision the big picture. I find that instructional development, and research and development have much more impact and are more enjoyable when I, and my research team, whatever size it may be, have established clear visions and missions. What is the goal of the program?

For me, a vision sets a picture of what I want the world to be like when the training or research program are over. It is a broad set of achievable goals, that once set and agreed to by the team, customers, and users, should not be changed without great consideration. The vision should cover a period of years and an end date should be set. It defines the "what" that the team and I will be doing to achieve the goals.

The mission is "how" we will accomplish the "what." Missions can be changed frequently if necessary. We may accomplish one mission goal on the way to the vision achievement, and then decide for the next step to take a different path to move towards the "what". 
A good example of this vision/mission goal process was the path we set in our Air Force Research Laboratory for Distributed Mission Training. Our vision was a future state where every aircrew in the Air Force would be able to train in a realistic simulator, in real time, with a complete set of instructional features and performance measurement as required for effective training. Once that vision was established and accepted by the team, its customers, and users, we stuck to it for a number of years. Disruptions in Lab budgets, departure of key scientists and engineers, and wavering on the part of our Air Force customers (military and civilian personnel at key decision making levels come and go on a regular basis) did not dissuade us from the vision. We focused all of our programs (missions) on the big vision. We finally achieved a major milestone in the Distributed Mission Training program when several Four Star Generals said they wanted the capability for their Commands, and the AF started to devote major budget investments to implementing the vision. A training revolution occurred not just in the Air Force, but across the DoD and in allied countries.

\section{Pay attention to front end}

analysis. The first step in the ISD model described earlier is Analysis. ISD Analysis consists of three main steps.

Needs assessment. Needs assessment is conducted when a job performance problem has been identified. Needs assessment involves a systematic identification of solutions to performance problems. The assessment determines the root cause of the problem, then proposes a solution. The problem may be due to inadequate training, poor job documentation, poor equipment, lack of motivation, or other organizational issues.

Job analysis. Job analysis is a systematic method of listing all the tasks necessary to perform a specific job. These tasks represent the foundation on which we construct performance-based training objectives, course content, and evaluation instruments. Simply put, the job analysis provides a detailed "picture" of the job to be trained. The job analysis also provides information about entry-level skills and possible prerequisites.

Target audience analysis. This step identifies characteristics that affect trainee learning. It includes trainees' educational background, previous training experiences, relevant work experiences, and motivation for training. This information enables designers to customize training for the intended audience.

Training requirements and outcomes. Training requirements are the knowledge and skills that must be learned. Training outcomes are tasks that trainees must demonstrate to given standards in order to ensure competence on the job.

Unfortunately, some customers of training developers and supervisors of training developers rush to get the front end analysis done so the design phase of instruction and simulator design can begin. It always reminded me of the old Fram oil filter commercial where the shop mechanic says something like, "You can pay me a little extra now for a quality filter, or you can pay me a lot more later for a ruined engine." Front end analysis in training development is like that. Work hard to convince managers and customers that in the long run spending the time and resources to do a quality front end analysis is fully worthwhile. I have seen multi-million-dollar training simulators sitting unused because the training they deliver is not what the task or job needs

\section{Desperate need for learning} retention research. After 100 plus years of learning research we know a tremendous amount about how learners acquire knowledge and skills. We don't know nearly as much about the decay rate and retention of those knowledge and skills. Having done some learning retention research with humans, I can say that it is not easy. We can't put the human subjects in a controlled setting during the retention period after we have measured how well they acquired the learning. They have lives and must go about their daily business. We can't control what influences they come under during that retention period, or even if somehow they have practiced with the knowledge and skills 
they acquired. In addition, it is difficult to get all of the subjects back at the end of the retention period. Despite these difficulties, it is important to do such studies. I imagine that for every 20 learning acquisition studies that have been done, we probably don't have more than one retention study. How can we judge when sustainment training is required if we do not have good retention models with valid data?

\section{Formative evaluation for} simulation-based training devices. Developing effective training simulators is no different than developing any other training. There is need for formative evaluation of effectiveness through different phases of the development process. Use mock-ups, breadboards, rapid prototyping tools, even pencil drawings with subjects who share the same entry and learning characteristics with the eventual training population. Any insight you can get into how the test subjects are understanding the learning objectives and how they will use the eventual training device and training features is valuable. Waiting until the device is completely finished to check whether its training is effective can waste huge amounts of time and money if the training is ineffective. The earlier the researcher can gain insight to the nature of the functions, tasks and trainees, the better will be the ultimate training system result.

How much simulation fidelity is enough? In much of our Lab work we attempted to ask and answer the question that senior decision makers (e.g., Congress, the Pentagon, top military leaders) wanted to know, "How much simulation is enough?" This question stemmed largely from a desire to provide the necessary training capabilities at affordable prices. The rationale for the question grew from a desire to provide just the right amount of fidelity and no more. I always felt that question, while well intentioned, was short sighted. Modern aircraft and their sub-systems are constantly changing. New capabilities are often added to military aircraft and other materiel. What might be enough simulation fidelity today, may not be enough in a fairly short time. None the less, we heard the decision maker's call for "how much is enough" kind of R\&D and strove to produce findings that might answer the question.

\section{Training of instructors for simulation based training must be sustained throughout a training device} lifetime. The effectiveness of a training device reduces as each new generation of instructors appears. New instructor training is usually produced for a training device when it is first delivered. The manufacturer is usually tasked to provide hands on training to the instructors for the device. That training includes instruction about how best to operate the device using all of the instructional features and performance measurement tools. The organization that provides the simulator usually budgets for that type of training. However, it rarely budgets for a repeat of the training when a new generation of instructors takes over or the simulator is improved. The result is that each succeeding generation of instructors is taught by the previous generation in an informal manner. Instructor training documentation that may have been provided when the simulator was first delivered is often not used by following generations of instructors. Rules of thumb are applied more and more so that effectiveness of the training device continues to decline. It is important to convince the user organization that they must budget for instructor training as a matter of course for as long as the device is used.

\section{Pilot tests of research designs are} crucial. I have seen a number of researchers, both experienced and otherwise, run experiments with their research subjects before they have pilot tested their research designs. That is typically a mistake. Doing behavioral research is fraught with potential chance error. Researchers can substantially reduce these errors if they first run one or more pilot tests. Doing research with humans is difficult partly because human variability itself can vary over time. Doing 
pilot studies also consumes time and resources, but we need to remember the ancient adage repeated by the Fram filter mechanic. The more the researcher can do to identify research error that comes from a faulty design, the better will be the resulting research and its findings.

Know what color of R\&D funding you are seeking. Decide whether you are doing basic or applied research - if nothing else this distinction matters greatly to program managers in charge of funding. Basic research is in search of truth, often without concern of whether the resulting truths can be immediately useful. This type of research lays the foundation for theory building, which I believe is crucial for evaluation. Applied research uses basic research findings and resultant theories for exploratory research. Exploratory research provides a chance to test possible training solutions, without necessarily having a particular learning problem or user. Successful findings and developments can then be moved to the advanced exploratory phase.

A researcher must decide where their research falls on the scale described above. Government funding for R\&D all comes in a certain "color"- a funding type designation. I've seen many researchers try to get research funding without attending to the type of money allocated for it, and they were rarely successful in their quest.

Mind the Gap. For those who have ridden the Underground subway in London that phrase will be familiar. The sign is posted all over the Underground reminding passengers that there is a gap between the platform and the train. Ignore that gap at your peril. In all instructional $R \& D$ there is a gap between the work to develop it and its successful implementation in the training world. A researcher, especially working in the applied research area should start early to build a bridge to the eventual customer/user. On many occasions I've seen scientists frustrated after producing great $\mathrm{R} \& \mathrm{D}$, only to find customers and/or users not ready for the new knowledge or device, or not even able to see the need for it. Many R\&D products are left on the shelf because the gap wasn't minded. My rule is that a researcher should start a research project devoting about $15 \%$ of their time to gap minding. As the project progresses towards its transition, the researcher should steadily increase gap minding time while spending less and less time on the actual training product or research. This transition must be thought through carefully or the researcher runs the risk of producing a product nobody really wants, or producing a product late to the customer/user's need.

Embrace the bureaucracy! Any system needed to produce viable training, training research, and training devices has its bureaucratic rules - the systems that provide resources for our work, and often the requirements for the expenditure of those resources. I've seen many developers and researchers spin their wheels toward progress because they didn't like the rules and tried to ignore or short circuit them. With experience, a researcher can usually find a path to short circuit some rules, but that comes from substantial amounts of experience with the system. Early on, after a couple of aborted attempts to ignore the rules, I determined that the energy required to be successful at gaming the bureaucracy was not worth the time and effort. I finally decided it was easier to simply follow the rules, no matter how nonsensical they appeared, and spend my energy getting the real job done. As you rise in management you may eventually agree with me.

Multi-discipline teams. Research psychologists and educators need to learn how to be valuable members of multidisciplinary teams. These teams can include people from other behavioral sciences, engineers, computer scientists and programmers, medical scientists, subject matter experts, and a vast variety of other disciplines. Learn to form teams, learn from people with management skills, learn to listen to the concerns from team-mates from other disciplines. That last lesson learned came to me the hard way. The first multi-disciplinary 
team I led did not do well, at least partly because I was not truly trying to understand the problems team members were relating to me. Be flexible in leading and be prepared to make mid-course corrections if it appears your team is not accomplishing its mission toward the larger vision.

\section{Professional societies. Get} involved in professional societies that meet your interest. I met some of my closest professional colleagues and friends by volunteering to work on society committees. They have been a steady influence on my work and a great pool of expertise that I have tapped many times. Go to as many society meetings as your budget and time will allow. It is well worth it.

Break bad news early. There are an infinite number of things that can go wrong with a development or research project. I have found it is best to break bad news early to bosses, customers, funders, and users. I have tried to lead my team in fixing whatever issue might arise, while at the same time letting the various stakeholders know that an issue might be developing. I have tried the route of keeping the bad news to myself for a long time in hopes that the problem could be fixed. I found that the surprise factor only gets bigger as I tried to keep the problems to myself. A little bad news early is usually better than a lot worse news later on.

\section{Be serious about managing your}

career. This I learned the hard way. When I began my career I had the naïve belief that if I did my job to the best of my ability and produced good results, the "system" would reward me with awards and promotions. It didn't take me long to realize that happens on occasion, but it is not the norm no matter where you work. Don't count on anyone else to manage your career. It is up to you to figure out where you want to go, and then what you must do to get there. Perhaps it is receiving certain types of training, working on committees, moving to a new location, being involved in "high profile" projects, or getting quality mentors in the system. There is certainly nothing wrong with a person deciding early on to remain a researcher, and not move up the management chain. But, I've mentored many scientists who, in their mid-career years, decided they wanted to move up the organization. However, because they hadn't done what was necessary earlier in their careers to put themselves in competitive positions for promotion they were disappointed to find that the odds of advancement were not what they wished. Develop good situational awareness concerning your job path and make the decisions you need to make. No one should be as interested in your career development as you are.

Leave a legacy. One of my favorite books is Stephen R. Covey's The Seven Habits of Highly Effective People (2004). In this book Covey reported on in-depth research he had done with highly effective people. He lays out seven habits that he says were the hallmark of all successful people.

- Be proactive

$\circ$ Begin with the end in mind

- Put first things first

- Think Win-Win

- Seek first to understand, and then seek to be understood

- Synergize

- Sharpen the saw

In his next book, The $8^{\text {th }}$ Habit: From Effectiveness to Greatness he describes how "leaving a legacy" should be a major goal for all professionals. That is a lesson I have learned by having the opportunity to lead and mentor a variety of younger colleagues as a government science leader and as an adjunct faculty member. I had some wonderful leaders in my life including my father, Dale H. Andrews, Scout leaders, religious leaders, and scientists such as Robert Gagne. These leaders left a shining legacy for me to examine and take inspiration. Strive to build your professional career so that you too can leave a legacy for the many people who you will influence in our field. 


\section{Wrap Up}

I've now been retired from the

Department of Defense for over five years, but continue consulting in DoD training. I have worked on training programs for the Naval Special Warfare Command, conducted a cognitive task analysis of the Unmanned Aerial Vehicle (UAS) (drones) piloting task, and developed training in cyber security. I also teach courses for a number of universities online. All of these tasks have not only kept my head in the training game, but they also allow me to work with old friends from DoD days. I still love training research and development, and intend to stay in it until I can't do it anymore.
Would I recommend working for the DoD? Working for the DoD is generally well supported with resources such as funding, lab equipment, subject matter expertise, and technical partners. In addition, the work has national and international importance because of its direct effect on the security effectiveness of our armed forces. During my career I have been pleased to provide our military with quality science and technology products to help make the training of our personnel and allies the finest in the world. We in the training and training science business have a great responsibility. I highly encourage any readers who have been interested in some of the work I have related to consider a career working for the military of our nation.

\section{References}

Alexander, T., Goldberg, S. L., Andrews, D. H., Hourlier, S., Koerhuis, C., Magee, L. F., . . Sottlilare, R. (2014). Improving Human Effectiveness Through Embedded Virtual Simulation. NATO Science and Technology Organization. Technical Report TR-HFM-165.

Andrews, D. H. (1988). Relationships among simulators, training devices, and learning: A behavioral view. Educational Technology, 1(28), 48-53.

Andrews, D. H. (2000). Distributed mission training. In W. Karwowski (Ed.), International encyclopedia of ergonomics and buman factors. Philadelphia, PA: Taylor and Francis.

Andrews, D. H. (2005). Distributed simulation training for teams. In N. Stanton, A. Hedge, K. Brookheair, E. Salas \& H. Hendrick, (Eds.) Handbook of Human Factors and Ergonomic Methods. London, England: Taylor \& Francis.

Andrews, D. H. \& Bell, H. (2000). Modeling and simulation applications to training. In S. Tobias and D. Fletcher (Eds.), Training and Retraining handbook. Washington, DC: American Psychological Association, Division 15 (Educational Psychology).

Andrews, D. H., Carroll, L. A., \& Bell, H. H. (1995). The future of selective fidelity in training devices. Educational Technology, 35(6), 32-36.

Andrews, D. H, \& Craig, S. (Eds.) (2015). Readings in training and simulation. Vol. 2: Research articles from 2000-2014. Santa Monica, CA: Human Factors and Ergonomics Society.

Andrews, D. H., Freeman, J., Andre, T. S., Feeney, J., Carlin, A., Fidopiastis, C. M., \& Fitzgerald, P. (2013). Training organizational supervisors to detect and prevent cyber insider threats: Two approaches. International Conference on Software Testing, Verification and Validation (ICST), EAI Endorsed Transactions on Security and Safety, 13(1-6), e4. Available at http://www.eudl.eu/journal/sesa

Andrews, D. H. \& Goodson, L.A. (1980). A comparative analysis of models of instructional design. Journal of Instructional Development, 3(4).

Andrews, D. H., Herz, R. P., \& Wolf, M. B. (Eds.) (2010). Human factors issues in combat identification. London, England: Ashgate Publishers.

Andrews, D. H., Hull, T., \& Demeester, K. (Eds.) (2010). Storytelling as an instructional method: Research perspectives. Rotterdam, NL: Sense Publishers.

Andrews, D. H., \& Roessingh, J. J. (2011). Training management in virtual embedded simulations. Proceedings of the $22^{\text {nd }}$ International Training Equipment Conference. Cologne, Germany. 
Andrews, D. H., Singer, M., Ozkaptan, H., \& Hofer, R. (1987). Optimization of training systems and subsystems: Models, methods and data. Proceedings of the National Security Industrial Association Conference on Military Personnel and Training. Luxemburg.

Andrews, D. H., Waag, W. L., \& Bell, H. (1992). Technologies for team training. In R. W. Swezey \& E. Salas (Eds.), Teams: Their training and performance. Englewood Cliffs, NJ: Ablex.

Andrews, D. H. \& Windmueller, H.W. (1986). Lock-step vs. free-play maintenance trainers: Definitions and issues. Educational Technology, 7(26), 29-34.

Best, C., Galanis, G., Kerry, J., \& Sottilare, R. (Eds.) (2013). Fundamental Issues in Defense Training and Simulation. London: Taylor and Francis.

Branson, R. K., Rayner, G. T., Lamarr, J., Cox, L., Furman, J. P., King, F. J. \& Hannum, W. H. (1975). Interservice procedures for instructional systems development. National Technical Information Service. ADA 019 486. Retrieved from http://www.dtic.mil/dtic/tr/fulltext/u2/a019486.pdf

Cannon-Bowers, J. A., \& Salas, E. (2001). Reflections on shared cognition. Journal of Organizational Behavior, 22, 195-202.

Cannon-Bowers, J. A., Salas, E., \& Converse, S. A. (1990). Cognitive psychology and team training: Shared mental models in complex systems. Human Factors Society Bulletin, 33(12), 1-4.

Charles, J. P. (1984). Design guidelines for trainer instructor/operator consoles. Naval Training Systems Center, Orlando Fl., NAVTRASYSCFN 83-C--0087-1. DTIC Technical Report Accession Number AD-A171637.

Chegg, (n.d.). Relative motion. Retrieved from http://www.chegg.com/homeworkhelp/definitions/relative-motion-5

Conant, J. (2014). MANPRINT program focuses on integrating buman element. Retrieved from http://www.arl.army.mil/www/?article $=2470$.

Cooke, N. J., Gorman, J. C., Myers, C. W., Duran, J., \& Andrews, D. H. (2013). Retention of team coordination skill. In W. Arthur, E. A. Day, W. Bennett, \& A. M. Portrey (Eds.), Individual and team skill decay: State of the science and implications for practice. New York: Routledge Academic.

Cooke, N. J., Pedersen, H. K., Connor, O., Gorman, J., \& Andrews, D. H. (2006). Acquiring teamlevel command and control skill for UAV operation. In E. Salas (Series Ed.) \& N. Cooke, H. Pringle, H. Pedersen, \& O. Connor (Eds.), Advances in human performance and cognitive engineering research: Vol 7. Human factors of remotely operated vehicles. (pp. 285-297). Oxford: Elsevier.

Covey, S. R. (1998). The 7 habits of highly effective people. Provo, UT: Franklin Covey.

Covey, S. R. (2004). The $8^{\text {th }}$ habit: From effectiveness to greatness. New York: Free Press.

Endsley, M. R. (1995). Toward a theory of situation awareness in dynamic systems. Human Factors, 37, 32-64.

Fitzgerald, P. C., Andrews, D. H., Crabtree, M. S., Doyal, J. A., Meador, D. P., \& Walsh, W. J. (2008). Incorporating training effects in modeling and simulation software. Proceedings of the Sixth Annual Conference on Systems Engineering Research. Los Angeles, CA.

Fitzgerald, P. C., Andrews, D. H., Crow, B., Diedrichs, R., Karp, M. R., \& Stewart, K. (2007, April). An investigation of certified flight instructor competencies. Presented at the International Symposium on Aviation Psychology, Dayton, $\mathrm{OH}$.

Freud, S. (1899/1913). The interpretation of dreams. Trans. A.A. Brill. New York: Macmillan.

Gagne, R. M. (1954). Training devices and simulators: Some research issues. American Psychologist, 9(3), 95-107.

Gagne, R. M. (1972). The conditions of learning ( $3^{\text {rd }}$ Ed.). New York. Holt, Rinehart and Winston. Gagne, R. M. (1985). The conditions of learning and theory of instruction. $4^{\text {th }}$ ed. New York: Harcourt Brace. 
Gagne, R. M., Briggs, L. J., \& Wager, W. W. (1992). Principles of instructional design. (4 ${ }^{\text {th }}$ ed.). Orlando, Fl., Harcourt, Brace, Jovanovich.

Greitzer, F. L., Moore, A. P., Cappelli, D. M., Andrews, D. H., Carroll, L. A. \& Hull, T. D. (2008). Combating the insider threat. Security and Privacy, 6(1), 61-64. Institute of Electrical and Electronic Engineering's Computer Society.

Hanley, M. J. \& Andrews, D. H. (1987, April). Evaluation of the effectiveness of a table-top simulator device as a ship handling trainer. Paper presented at the 1987 Society for Computer Simulation - Eastern Simulation Conference. Orlando, FL.

Hays, R. T., \& Singer, M. J. (1989). Simulation fidelity in training and system design: Bridging the gap between reality and training. New York: Springer-Verlag.

Hoffman, R. R., Ward, P., Feltovich, P. J., DiBello, L., Fiore, S. M., \& Andrews, D. H. (2014). Accelerated learning: Training for high complexity in a complex world. New York: Academic Press.

Instructional Design Central. (2016). The ADDIE model. Retrieved from: http://www.instructionaldesigncentral.com/instructionaldesignmodels

Instructional Systems Development. (N.D.). Air University. Retrieved from http://www.au.af.mil/au/awc/awcgate/doe/isd/paper.htm

JP 3-05.1 Joint Special Operations Task. Force Operations. 26 April 2007 Retrieved from http://fas.org/irp/doddir/dod/ip3 05 01.pdf

Morrison, J. E., \& Fletcher, J. D. (2002). Cognitive readiness. Institutes for Defense Analysis P-3735. Retrieved from http://www.dtic.mil/dtic/tr/fulltext/u2/a417618.pdf

Orlansky, J., \& String, J. (1981). Cost-Effectiveness of Maintenance Simulators for Military Training. Final. Report. Institute for Defense Analysis, Arlington, Va. Department of Defense, Washington, D.C. IDA-P-1568 MDA-903-79-C-0202

Paris, C. R., Salas, E., \& Cannon-Bowers, J. A. (2000). Teamwork in multi-person teams: A review and analysis. Ergonomics, 42(8), 1052-1075.

Robinson, P. W. (1976). Fundamentals of experimental psychology: A comparative approach. Upper Saddle River, N.J.: Prentice-Hall.

Radon. R. (n.d.) Operations research and optimization: A primer. Retrieved from http://www2.isye.gatech.edu/nci-nsf.orart.2002/pdf-files/Rardin.primer.pdf

Salas, E., Cooke, N. J., \& Rosen M.A. (2008, June ). On Teams, Teamwork, and Team Performance: Discoveries and Developments. Human Factors, 50(3).

Salas, E., \& Fiore, S. M. (Eds.). (2004). Team cognition: Understanding the factors that drive process and performance. Washington, DC: American Psychological Association.

Semple, C.A., Cotton, J. C., \& Sullivan, D. J. (1981). Aircrew training devices: Instructional support features. Air Force Human Resources Laboratory. AFHRL TR 80-58. Government accession number AD-A096 234.

Singer, M. J. (1993). The optimization of simulation-based training systems: A review of evaluations and validation of rule bases. U.S. Army Research Institute for the Behavioral and Social Sciences. Research Report 1653.

Sticha, P. J., Blacksten, H. R., Buede, D. M., Singer, M. J. \& Gilligan, E. L. (1990). Optimization of simulation-based training systems: Model description, implementation, and evaluation. Human Resources Research Organization, Alexandria, Va. DTIC Accession Number ADA 237266.

Swezey, R. W., \& Andrews, D. H. (Eds.) (2001). Training and simulation: A thirty-year perspective.Santa Monica, Ca. Human Factors and Ergonomics Society.

Wilson, K. A., Salas, E., \& Andrews, D. H. (2010) Preventing errors in the heat of battle: Formal and informal learning strategies to prevent teamwork breakdowns. In Andrews D. H., Herz R. P., \& Wolf M. B. (Eds.), Human factors issues in combat identification (pp. 1-28). Aldershot, UK: Ashgate. 


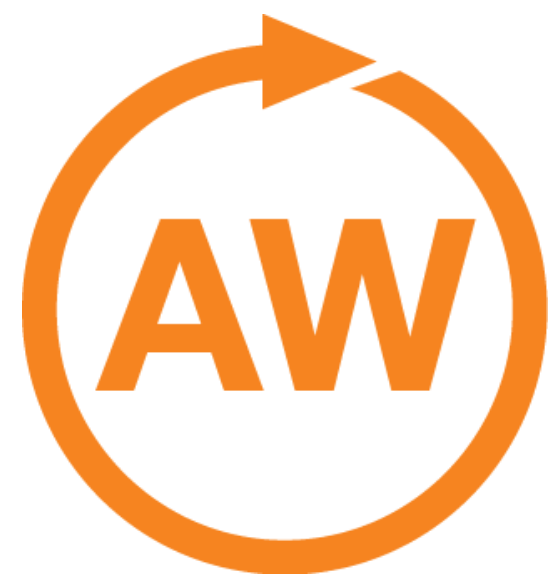

\section{About Acquired Wisdom}

This collection began with an invitation to one of the editors, Sigmund Tobias, from Norman Shapiro a former colleague at the City College of New York (CCNY). Shapiro invited retired CCNY faculty members to prepare manuscripts describing what they learned during their College careers that could be of value to new appointees and former colleagues. It seemed to us that a project describing the experiences of internationally known and distinguished researchers in Educational Psychology and Educational Research would be of benefit to many colleagues, especially younger ones entering those disciplines. We decided to include senior scholars in the fields of adult learning and training because, although often neglected by educational researchers, their work is quite relevant to our fields and graduate students could find productive and gainful positions in that area.

Junior faculty and grad students in Educational Psychology, Educational Research, and related disciplines, could learn much from the experiences of senior researchers. Doctoral students are exposed to courses or seminars about history of the discipline as well as the field's overarching purposes and its important contributors. .

A second audience for this project include the practitioners and researchers in disciplines represented by the chapter authors. This audience could learn from the experiences of eminent researchers-how their experiences shaped their work, and what they see as their major contributionsand readers might relate their own work to that of the scholars. Invitations to potential authors were accompanied by Tobias' chapter in this series for illustrative purposes. Authors were advised that they were free to organize their chapters as they saw fit, provided that their manuscripts contained these elements: 1) their perceived major contributions to the discipline, 2) major lessons learned during their careers, 3 ) their opinions about the personal and 4) situational factors (institutions and other affiliations, colleagues, advisors, and advisees) that stimulated their significant work.

We hope that the contributions of distinguished researchers receive the wide readership they deserve and serves as a resource to the future practitioners and researchers in these fields. 


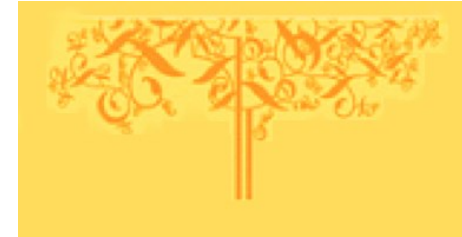

\title{
education review // reseñas educativas a multi-lingual journal of book reviews
}

editors: gustavo e. fischman / melissa cast-brede / gene $v$ glass

Supported by the Mary Lou Fulton Teachers College, Arizona State University

\author{
Acquired Wisdom \\ dited by
}

Sigmund Tobias J. D. Fletcher David C. Berliner

University at Albany Institute for Defense Analyses Arizona State University

State University of New York $\quad$ Alexandria VA Tempe AZ

\author{
Advisory Board Members \\ Gustavo Fischman, Arizona State University \\ Arthur C. Graesser III, Memphis State University \\ Teresa 1. McCarty, University of California Los Angeles \\ Kevin Welner, Colorado State University
}

\begin{abstract}
Education Review/Reseñas Educativas/Resenhas Educativas is supported by the edXchange initiative's Scholarly Communications Group at the Mary Lou Fulton Teachers College, Arizona State University. Copyright is retained by the first or sole author, who grants right of first publication to the Education Review. Readers are free to copy, display, and distribute this article, as long as the work is attributed to the author(s) and Education Review, it is distributed for non-commercial purposes only, and no alteration or transformation is made in the work. More details of this Creative Commons license are available at http://creativecommons.org/licenses/by-nc-sa/3.0/. All other uses must be approved by the author(s) or Education Review. Education Review is published by the Scholarly Communications Group of the Mary Lou Fulton Teachers College, Arizona State University.

Please contribute reviews at http://www.edrev.info/contribute.html.

Connect with Education Review on Facebook (https://www.facebook.com/pages/EducationReview/178358222192644) and on Twitter @EducReview
\end{abstract}

